\title{
COMMUNICATION ON THE ATTACHMENT AND THE . EARLY DEVELOPMENT OF MACROSCELIDES (=ELEPHANTULUS) ROZETI DUV., THE NORTH-AFRICAN JUMPING SHREW
}

\author{
BY \\ Dr. D. DE LANGE \\ Hubrecht Laboratory, Utrecht (Holland)
}

\section{INTRODUCTION}

This insectivore resembles in its conduct and appearance the North-African jumping mouse (Jaculus) which is, however, a rodent with folded molars and premolars.

The molar and premolar teeth are pointed as in other Insectivores. The upper molars are quinquetubercular (the cusps are placed in $\mathrm{W}$ form). $\mathrm{P}_{4}$ is molariform and the canini possess the same structure as the tritubercal premolars. The number of teeth is very large. In Macroscelides it is $42 \frac{3+\mathrm{I}+4+2}{3+\mathrm{I}+4+3}$

In connection with the jumping progression the hind limbs are elongated. This elongation is especially caused by the strong development of the tibia and the metatarsus. During the jumping progression the body is supported by the metatarsus and the toes. In rest the body is supported by both the anterior and posterior limbs, the fore limbs being rather well developed in contrast with the situation in Jaculus ${ }^{1}$ ). Macroscelides (Elephantulus) possesses 5 fingers and 5 toes.

The head is characterized by a naked proboscis 2 ), by long sense hairs on the cheek, by rather large eyes and large exterior ears with folded inner surface. The tail is rather long and thin and shows scales alternating with stiff hair groups. Probably it has the function to maintain the equilibrium during jumping and to facilitate the descent after jumping.

As Jaculus they are very shy creatures living in deserts and savannahs, with

I) The slow movement of these creatures takes place by both the anterior and posterior limbs and they behave therefore as quadrupeds.

2) The function of this organ is, of course, to look after insects and insect larvae in the soil and between the stones, the Macroscelidae always living in stony places. 
large ears, very sensible auditory organs and rather large eyes. In this way they are very sensible to exterior stimuli and they retire under stones at the slightest sign of danger.

During wartime prof. C. J. vAN. DER HORST (Johannesburg, Transvaal) has investigated a South-African form: Elephantulus myurus Jamesoni, which is

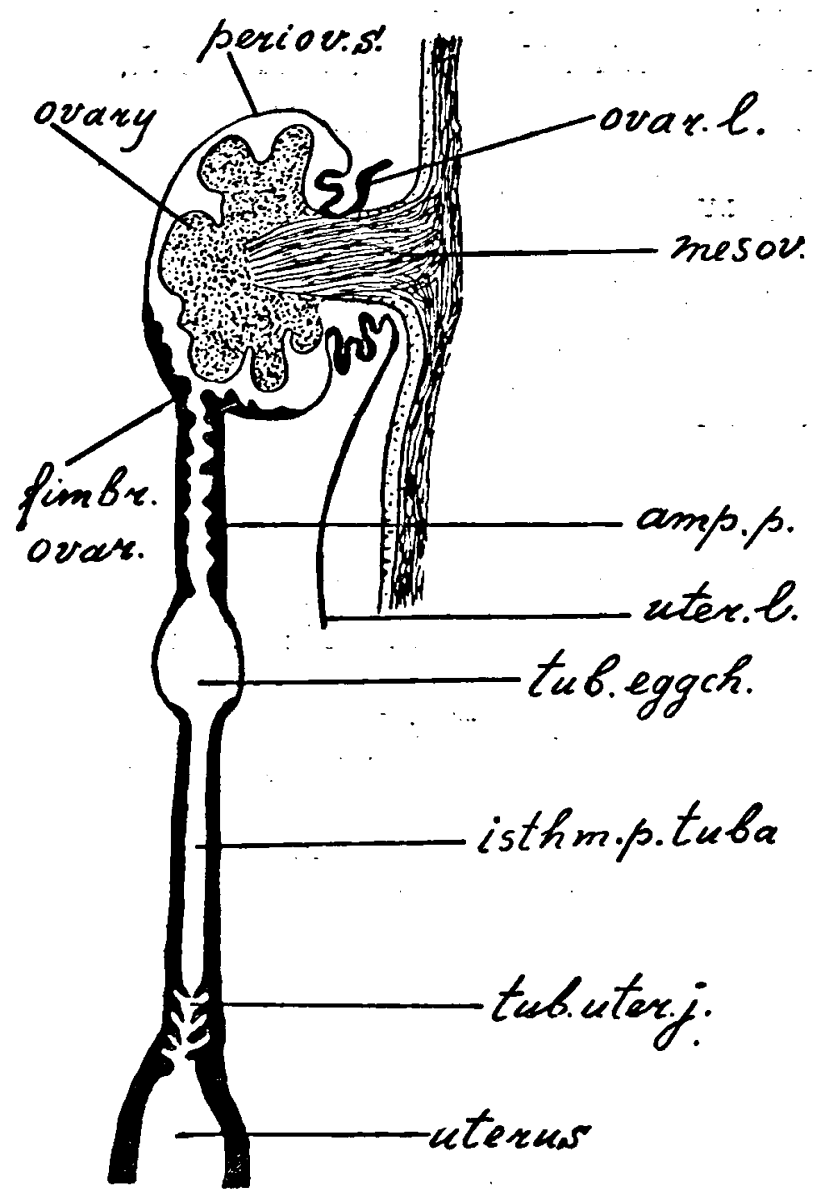

Fig. 1

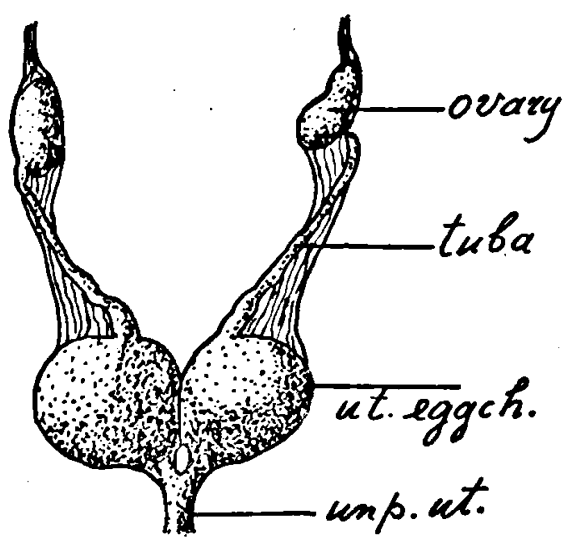

Fig. 2

rather common on the Highveld of Transvaal ${ }^{3}$ ). As I have now received copies of VAN DER HORST's investigations, I am able to compare the SouthAfrican and the North-African forms. The ripe eggs of Elephantulus myurus are liberated in a periovarial sac and are transmitted in the ampullary part of the oviduct by ciliary movement (see fig. I). In this part of the tube an egg chamber is formed where fertilizing takes place. It may contain 60 or more eggs. Many

3) I don't know if it is the same species described by other authors as Macroscelides probescideus Shaw, the common South-African form. 
of them develop to a stage of 4 cells but finally all these eggs die with exception of one egg in each oviduct developing to an embryo after attaching to the wall of the doubled part of the uterus (see fig. 2). Two embryo's in every pregnant individual is the normal situation but in some cases only one blastocyst develops.

In Macroscelides rozeti Duv. the normal number of developing blastocysts is 2 or 3 . In some cases the pregnant uterus shows 4 egg chambers but I get

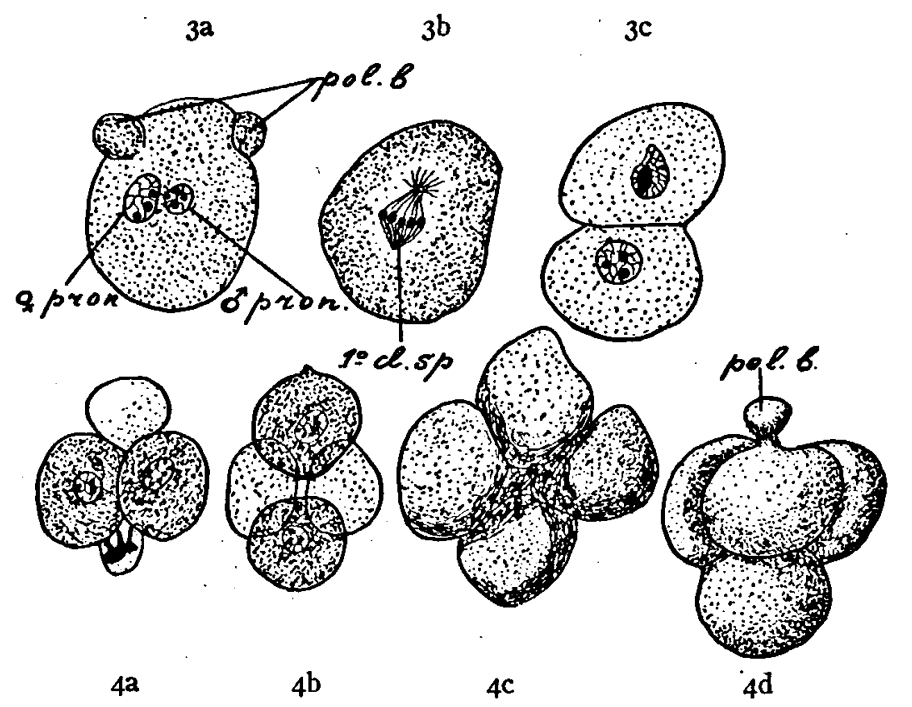

Fig. 3 (a, b, c) and fig. 4 (a, b, c, d)

the impression that one of the blastocysts is always degenerating. In exceptional cases only one egg chamber contains a normally developing embryo.

The collection of the Hubrecht Laboratory contains \pm 50 uteri, \pm 40 of which are pregnant. The latter number is perhaps not quite exact as pregnant and young puerperal uteri cannot be distinguished exteriorly and the egg chambers are not all cut into slides.

One specimen certainly is virginal. Two other specimina may be virginal but perhaps are very young stages. 43 specimina certainly are pregnant.

YOUNG STAGES OF DEVELOPMENT

(uterine egg chambers $5-12^{1 / 2} \mathrm{~mm}$ in section)

In the collection of the Hubrecht Laboratory cleavage stages are wanting, the youngest developmental stages being two-layered, but v. D. Horst disposed of several young specimina from the one-cell stage to the stage of 120 cells when the formation of the embryonic knot is starting. My knowledge of these early stages is therefore based on the publications of v. D. Horst Bijdragen tot de Dierkunde, Afl. 28. 
(1940). The eggs are naked, they are not surrounded by the zona pellucida which seems to be solved in the ampullary part of the tube or is thrown off with the corona radiata at the ovulation. For this reason the polar bodies-often are set free from the egg cell and this may also be the case with the cleavagecells mutually. In the tubal egg chamber egg cells with two pronuclei are very common (see fig. $3 \mathrm{a}$ ). The first cleavage spindle and two-celled stages also are to be met within the tubal chamber. The four-celled stage, however, is only found in the beginning of the paired uterus. The four cells may lie on a
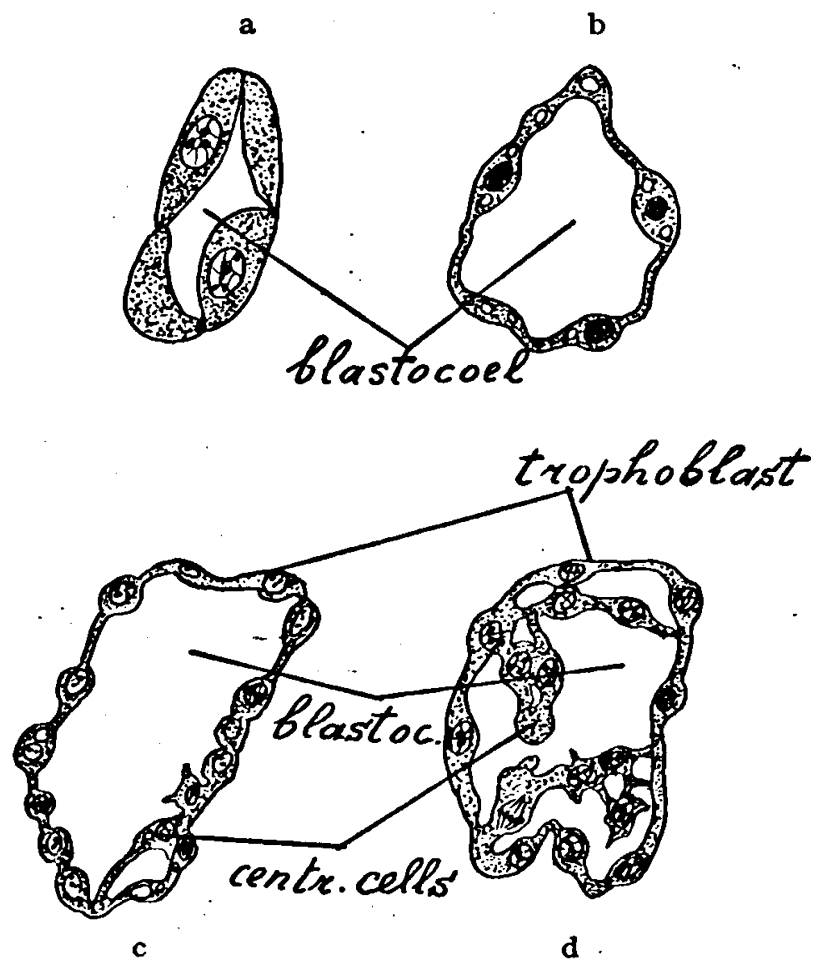

Fig. $5(a, b, c, d)$

concentric row or form a tetrahedron. If further development occurs the cells always are arranged in a tetrahedral way. Perhaps the four cells originally lie in the same plane and later on show a tetrahedral arrangement (see fig. 4a-d). In the four-celled stage the eggs descend to the doubled part of the uterus. As only one implantation site in the uterine horn occurs which is very narrow, only one egg in each horn adheres to the uterine wall (see fig. 2). The third division of the egg takes place after the four-celled stage has reached the implantation site. In this stage the blastocoel is forming (see fig. $5 \mathrm{a}$ ). In the uterine egg chamber the blastula accumulates liquid and the cells forming the unilaminar wall flatten (see fig. $5 \mathrm{~b}$, a stage of 32 cells). In a stage of \pm 120 
cells one may observe the first traces of the formation of the embryonic knot (see fig. 5c), some amoeboid cells separating from the wall of the blastula. Of course this description only holds good for Elephantulus myurus Jamesoni and differences with Macroscelides rozeti probably will occur f.i. the presence of three or four uterine egg chambers in the latter case. I think, however, that the cleavage as such will agree in both forms in the main points.

\section{I-FORMATION OF THE EMBRYONIC KNOT AND OF THE ATTACHMENT OF THE BLASTOCYST TO THE UTERINE WALL. UTERUS N. 2}

As was noted before at the stage of 120 cells the wall of the blastula separates amoeboid cells to the interior. This phenomenon is not restricted

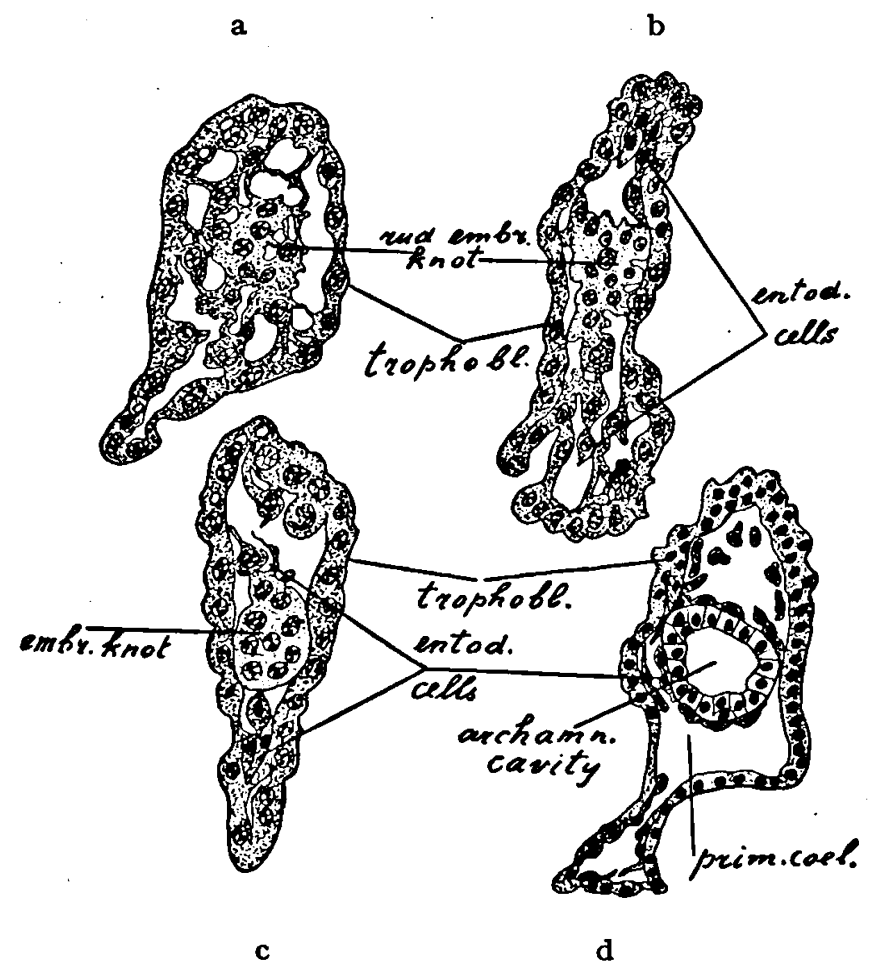

Fig. 6 (a, b, c, d)

to a special spot but occurs on the whole inner surface of the blastula. These cells show pseudopodia-like processes by means of which they are connected with each other and with the flat cells of the wall. In this way the original cavity of the blastula is filled by a loose reticulum of cells (see fig. $5^{d}, 6 a-d$ ). These cells concentrate on one side of the germinal vesicle. They partly lose 
pseudopodial processes and form a solid, round ball of cells : the rudiment of the embryonic knot (see fig. 6c). The entoderm cells increase in number by delamination of cells from the trophoblast. These cells envelop the embryonic knot and cover the wall of the blastocyst (see fig. $6 \mathrm{~d}$ ). In this stage an archamniotic cavity is formed in the embryonic knot by dehiscence (see fig. 6d). Probably the definite amniotic cavity is derived from the archamniotic one and is not a neoformation arising by amniotic folds.

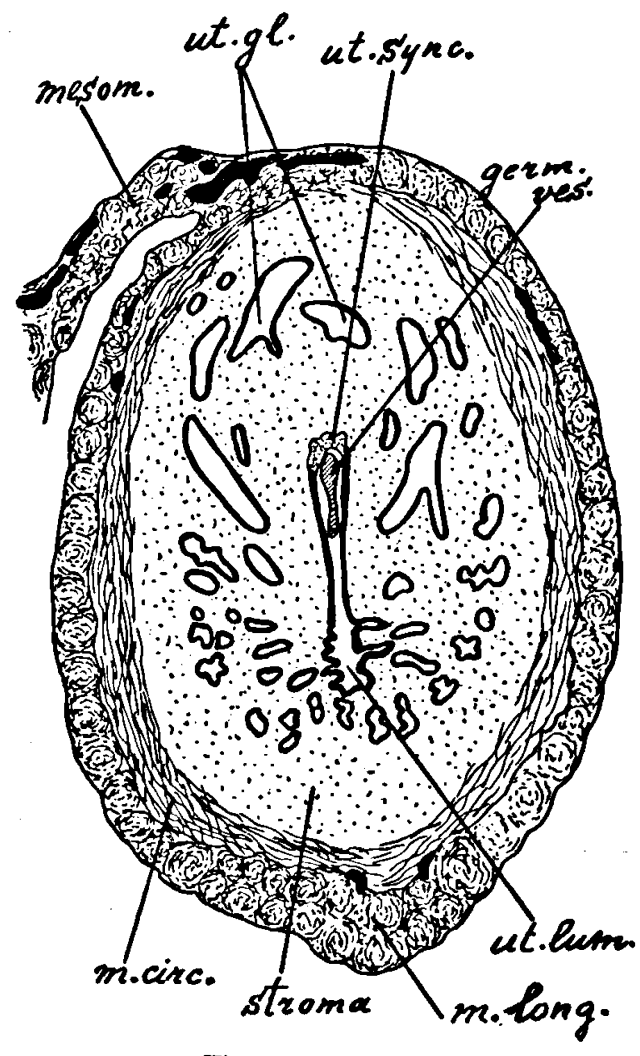

Fig. $7 \mathrm{a} \times 30$.

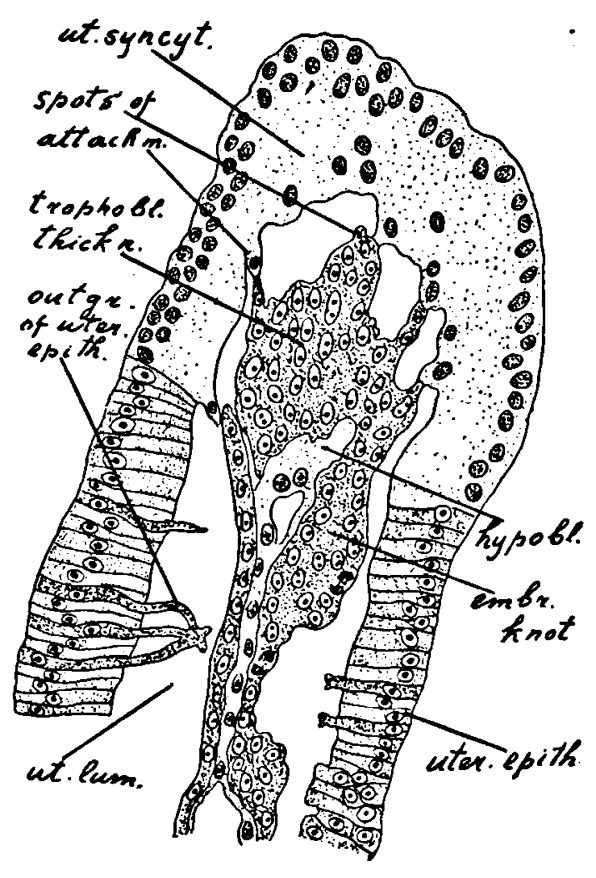

Fig. $7 \mathrm{~b} \times$ 100.

The following stage which shows some traces of attachment to the uterine wall, is the youngest stage present in the collection of the Hubrecht Laboratory (N. 2). The pregnant uterus shows three egg chambers of $\pm 2 \mathrm{~mm}$ in crosssection which is hardly larger than the cross-section of a virginal uterus.

The three egg chambers are indicated as $2 \mathrm{a}, 2 \mathrm{~b}$ and $2 \mathrm{~d}$. The last egg chamber is rather less developed as $2 \mathrm{a}$ and $2 \mathrm{~b}$. The egg chambers $2 \mathrm{a}$ and $2 \mathrm{~d}$ are cut parallel to the longitudinal axis of the uterus, $2 \mathrm{~b}$ is a cross-section.

The uterine lumen is stretched in the direction mesometrical-antimesometrical and is very narrow in the direction perpendicular to it (see fig. 7a and b). The uterine glands are enlarged especially at the mesometrical side (see fig. 
7a). The mesometrical side of the uterine epithelium has become syncytial (see fig. $7 \mathrm{~b}$ ). The greater part of the uterine wall shows high epithelial cells with distinct cell limits. The blastocyst is lying in the separate swollen, mesometrical part of the uterine lumen. It is connected with the remaining, antimesometrical part of the uterus by a narrow cavity (see fig. $7 \mathrm{a}$ and b). The blastocyst is consisting of a trophoblastic covering thickened at the mesometrical side and of an embryonic knot and scattered entoderm cells at the interior. The thickened part of the trophoblast shows connections with the uterine syncytium forming in later stages the foetal ectoplacenta. The embryonic knot is removed by this phenomenon (thickening- of trophoblast and forming of ectoplacenta) from the mesometrical pole to the lateral side. The definitive placenta is therefore lying at the mesometrical side of the uterus and at the ventral side of the embryonic knot (see fig. $7 \mathrm{~b}$ ).

Some of the uterine epithelial cells and the uterine syncytium show outgrowths which are partly not yet connected with the trophoblast. There may be present nuclei in these outgrowths (see fig. $7 \mathrm{~b}$ ). The connections trophoblast-uterine wall therefore are partly of maternal origin. Some of these outgrowths outside the egg chamber may possess a secretory character. Though the mucosa uteri is strongly swollen (about $3 / 4$ of the cross-section of the uterine wall is formed by the mucosa and only $1 / 4$ by the muscularis) the slight development of the blood vessels in this stage is remarkable. The stroma of the uterine wall is very massive and one cannot discover any large blood lacunae or blood vessels in it while these formations are met with in the mesometrium and in the mesometrical half of the muscularis. The thickening of the mucosa seems to be a real phenomenon of growing. It may be possible that the blood vessels and capillaries are squeezed by the shriveling caused by the fixation and therefore cannot be seen in the sections. If we accept this view the part of thickening caused by the blood inflation is not very large as may be demonstrated by the fact that in the fixed mucosa this part of the wall is much thicker than the muscularis.

On the other hand the increase of the uterine glands plays an important part in that of the mucosa. We must make a difference between the glands in the mesometrical half and those in the antimesometrical part of the uterine wall. The former are very large and not very numerous. There are 5-6 glands visible in a section. The epithelial cells are very flat and do not possess a light border.

The antimesometrical glands, on the other hand, are much smaller and more numerous (IO-I2 in a section). The covering cells are higher than the epithelial cells of the uterine wall and show a light border, a phenomenon in connection with the strong secretory function of these cells. The sections of these glands are distinctly notched so that they show a certain resemblance with the glands in the secretory phase of the uterus in man. At all events these glands are 
much larger than those of the virginal uterus and contribute to the increase of thickness of the young pregnant uterine wall (see fig. $7 \mathrm{a}$ )

Besides the extent of blastocyst and embryonic knot the differences between the series $2 a$ and $b$ on one side and the series $2 d$ on the other side consist of $I^{\circ}$ the more intimate and numerous connections between the trophoblast and the uterine syncytium in the series $2 a$ and $b$, especially in the series $2 a$ notwithstanding the fact the blastocyst of $2 b$ is larger than that of $2 a$.

$2^{\circ}$ the more strong development of the entoderm especially in $2 \mathrm{~b}$. In the series $2 a$ and $d$ the entoderm cells are not forming a continual layer but consist of loose meshes of cells and are failing under the embryonic knot. The blastocyst of series $2 \mathrm{~b}$ shows a typical closed yolk sac.

\section{II-TWO-LAYERED STAGE WITH DISTINCT ATTACHMENT OF BLASTOCYST, TROPHOBLAST PENETRATING INTO THE MUCOSA UTERI. EMBRYONIC KNOT SHOWS A RATHER LARGE ARCHAMNIOTIC CAVITY (UTERUS 45)}

The greater part of the uterine swelling of this stage especially at the mesometrical side is formed by very large uterine glands with a flat wall. The egg chamber with a rather narrow envelope of mucosa tissue is connected to the mesometrium by a number of lamellae containing numerous blood vessels (see fig. 8a). At the antimesometrical side the uterine wall shows the same character as in the swelling 2a-d (see fig. 8a).

Generally spoken the abundance of blood vessels is much greater than in the stages $2 a-d$ (see the numerous black dots at the mesometrical side of fig. 8a). Functionally this situation resembles the mesoplacenta of the aguti (Dasyprocta) as Hellmuth Becher has called the mobile connection of the blastocyst and the placenta of this animal with the remaining uterine wall. There are, however, morphological differences. In Dasyprocta there is only one connection of the blastocyst + placenta with the mesometrium, the mesoplacenta, in Macroscelides on the other hand there are numerous attaching lamellae (see fig 8a). Besides at the antimesometrical side the notched glands and the thick mucosa possess a rather normal appearance and the complex blastocyst-uterine epithelium is strongly anchored into the antimesometrical part of the uterine wall. The biological sense of these numerous vascular lamellae, the protection of the developing embryo against injurious shocks of these jumping animals will be quite the same as that of the mesoplacenta in the aguti.

The zone of attachment of the trophoblast is very narrow in one direction and rather large in the direction perpendicular to it. It is consequently ribbonlike and it is lying completely at the mesometrical side. The trophoblast pene- 
trates through the uterine syncytium into the mucosa and causes in this tissue the origin of a lens-like mass of trophospongia (see figs. 8a and b). The limits of this tissue are not very definite but it is plainly visible in \pm 30 sections.

The extension of the trophospongia does not coincide with that of the attachment of the trophoblast. Only in 18 sections attachment and trophospongia are visible in the same section.

The blastocyst of $45^{\mathrm{b}}$ is a little smaller. It is visible in 55 sections $(=550 \mu)$. The archamniotic vesicle shows a large cavity and a rather thin wall. There

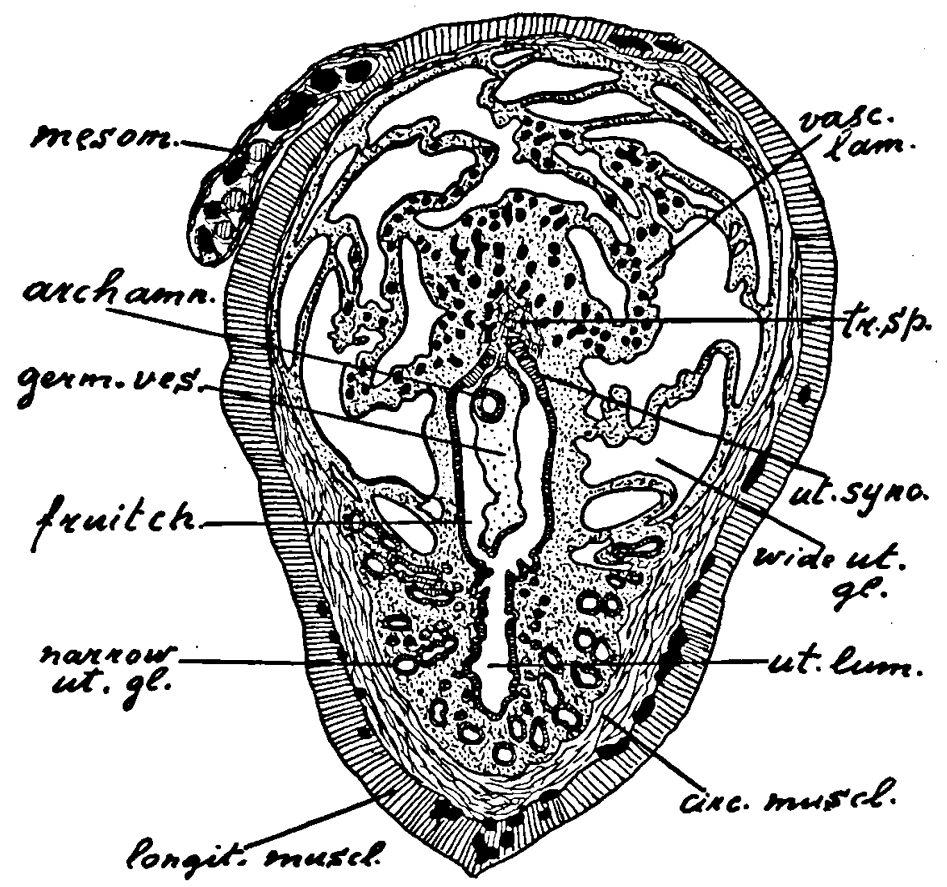

Fig. $8 \mathrm{a} \times 40$.

is no clear difference between the presumptive embryonic part and the covering of amnion ectoderm but topographically the situation of these parts may be defined. The amnion ectoderm is connected with the peripheral trophoblast though separated from it by entoderm cells, the embryonic rudiment is characterized by the presence of the yolk sac. The yolk sac is in both objects deformed by the fixation which has caused the formation of large coagulations inside and outside the yolk sac. The entodermal covering is torn to pieces at many spots. Probably the yolk sac fills in normal conditions the greater part of the blastocyst and the above-mentioned phenomena are artifacts caused by the fixation. 


\section{III-EMBRYONIC RUDIMENT WITH 7 OR 8 SOMITES.}

Heart-complex rather well developed. Anterior part of gut (pharynx and oesophagus) not in direct connection with the yolk sac but in the posterior portion of the intestine a large connection between gut and yolk sac is present. Cloaca with allantois evagination, the greater part of the allantois outgrowth being mesodermal. The yolk sac fills up about $2 / 3$ of the blastocyst, the remaining third part is formed by exocoel and amniotic cavity, the latter probably originating directly out of the archamnion. A proamnion is present. The enlarged uterine glands surround the whole

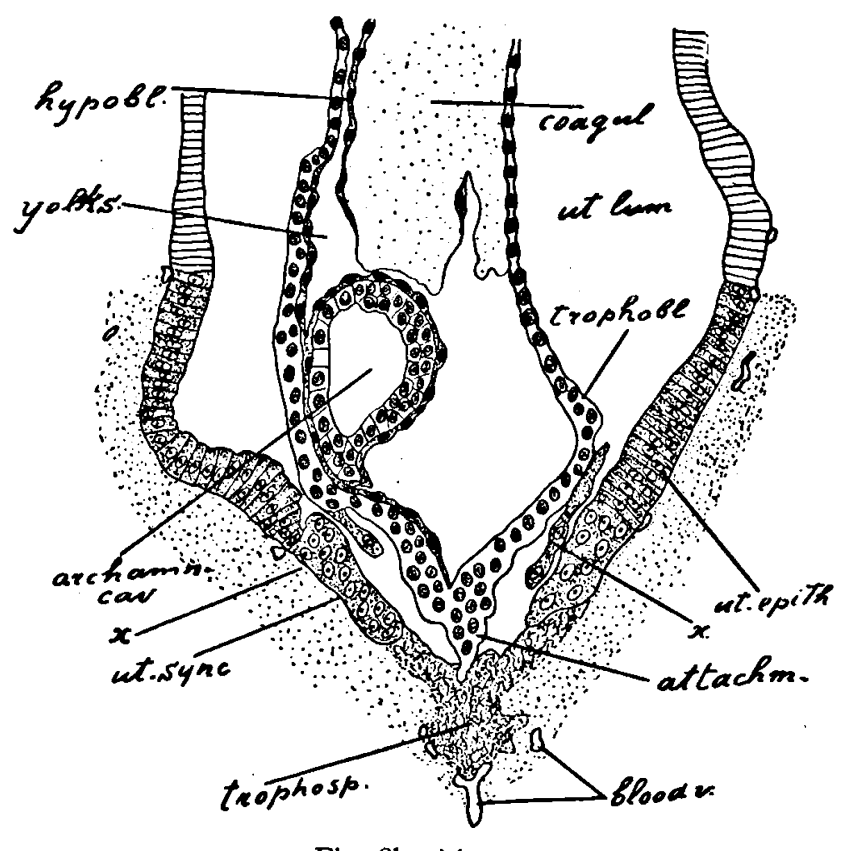

Fig. $8 b \times 100$.

uterine cavity and are not limited to the mesometrical side (see fig. 9a). A large ectoplacenta possessing a toadstool-form is penetrating into the mucosa uteri and forms the roof of the placenta. A ring of foeto-maternal symplasma encircles the place of attachment. Uterus N. 6.

Uterus $N$. 6 shows only one thickening indicated as $6 \mathrm{a}$. The object is cut transversely to the longitudinal axis of the uterus that is more or less parallel to the sagittal plane of the embryo. As the latter is curved and shows a torsion in the horizontal plane (see fig. $9 \mathrm{~b}$ ) of the embryo, this is only true for the midpart of the embryo.

Blastocyst N. 6a contains a closed amniotic cavity which may be derived directly from the archamniotic cavity. The proamnion is very large. The enteric canal possesses a rather large pharynx without clear visceral pouches 
but with the rudiment of the thyroid gland. A wide connection is present between the enteron and the yolk sac. A clear hindgut is rather wanting. The allantoic cavity is in direct connection with the lumen of the yolk sac. This cavity is rather large but the mesodermal part of the allantois is still much

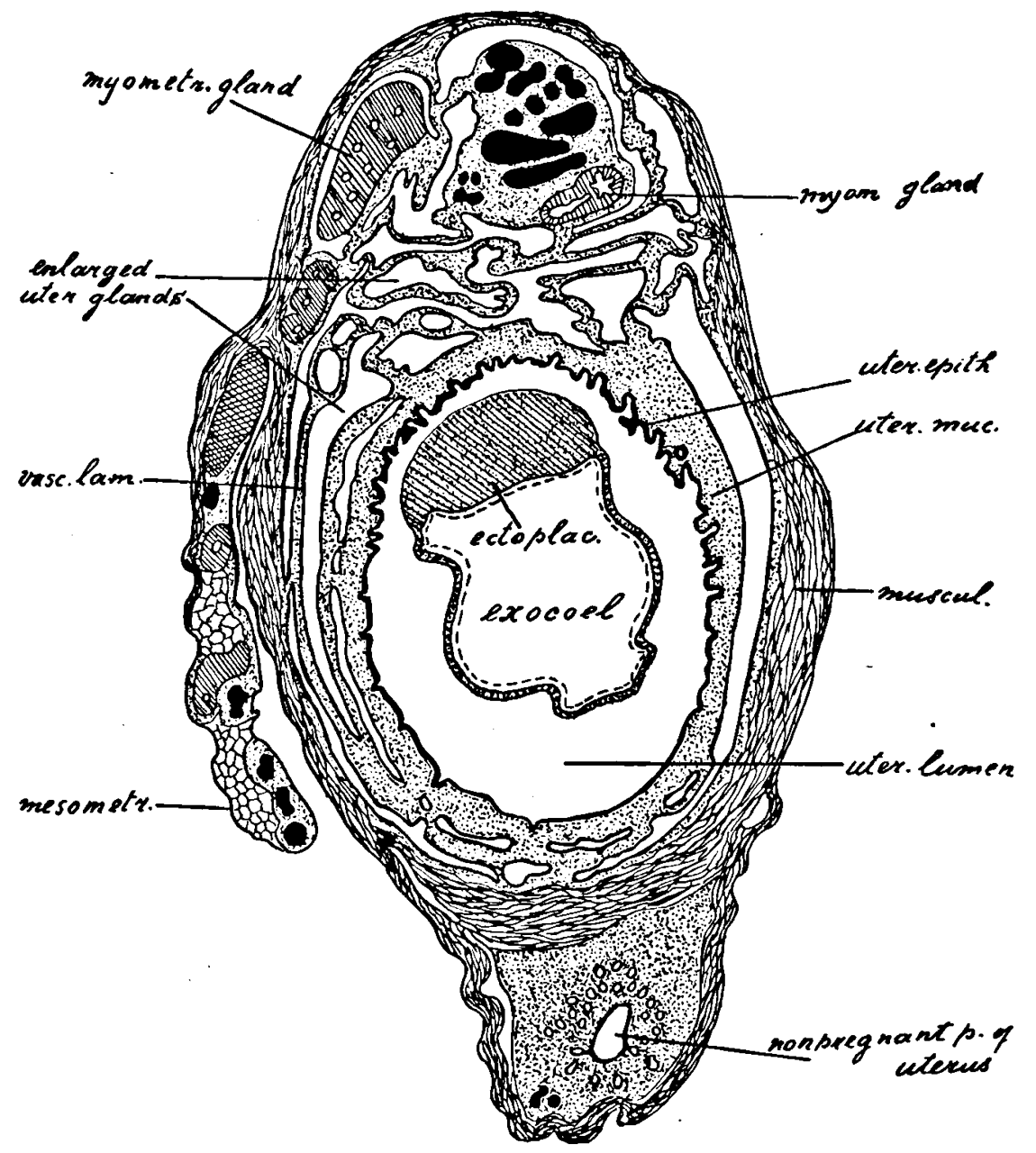

Fig. $9 \mathrm{a} \times 17$.

larger. It ends freely in the exocoel. In the wall of the allantois rudiments of blood vessels resp. blood spaces are occurring which are not yet in connection with the blood vessels of the heart. These are ending blindly. A real allantoic blood circulation therefore is not yet present. Oral and anal plates are present, they are not yet lacerated (see fig. 9c).

One may observe $7-8$ somites. The chorda shows little histological differentiation. The foremost part of the chorda is inserted in the roof of the pharynx, 


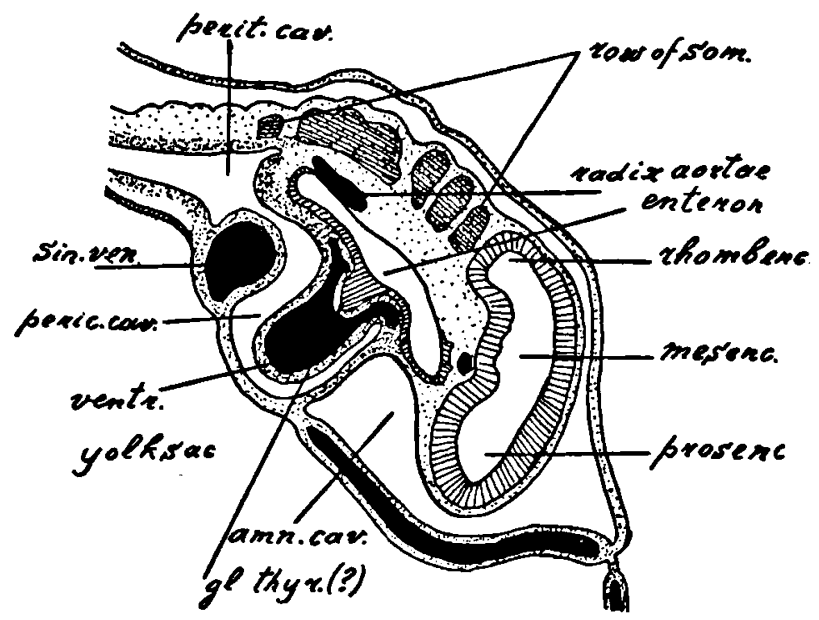

Fig. $9 \mathrm{~b} \times 30$.

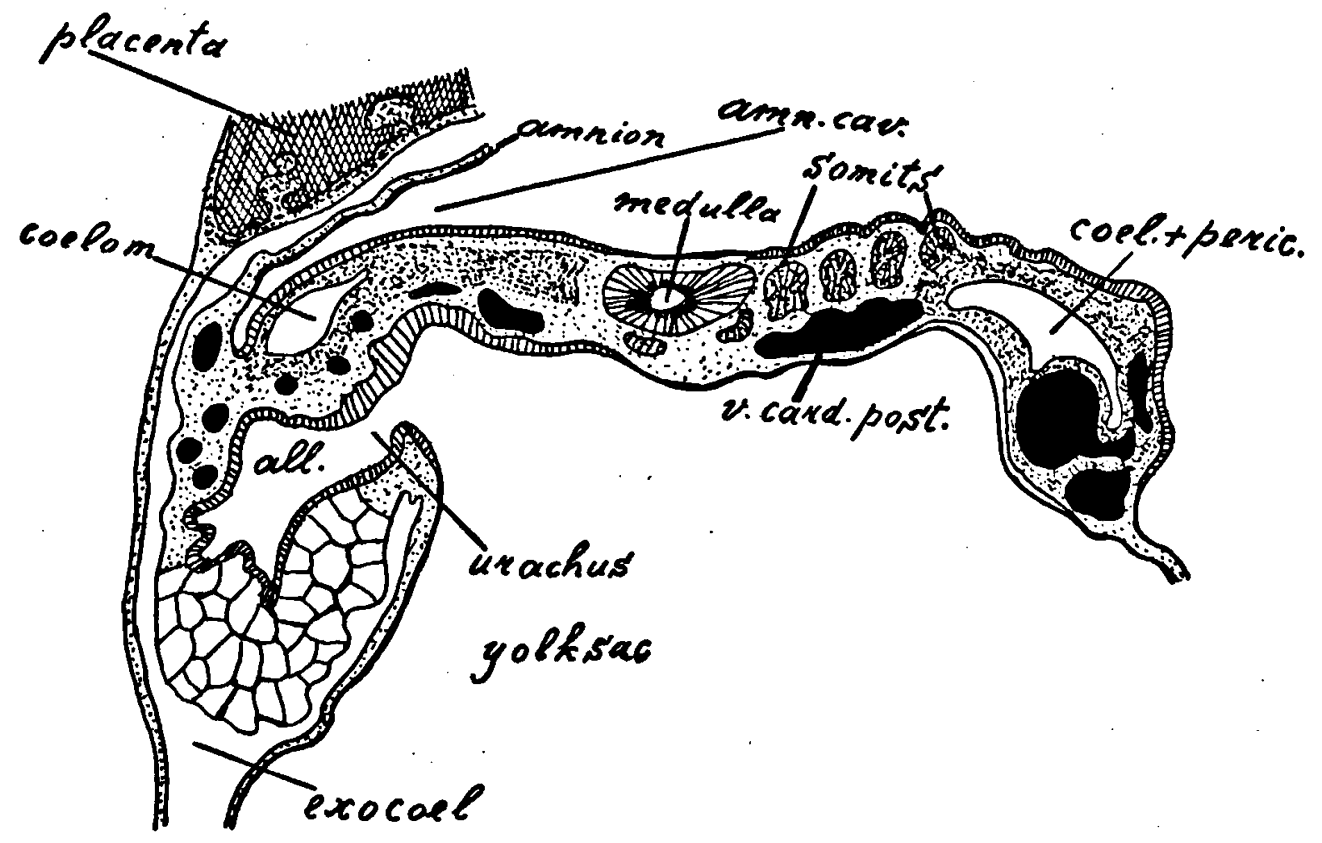

Fig. $9 \mathrm{c} \times 40$. 
the hindmost part is still connected with the mesodermal wings. The chordal tissue resembles the surrounding mesenchyme.

The rather large pericandial cavity is connected on both sides with the peritoneal cavity and with the exocoel. The peritoneal cavity is still wanting in the middle part of the embryonic region. In the hindmost part of this region a rudiment of the somatic coelom is already present (see fig. 9c).

The heart rudiment shows a not very distinct $\mathrm{S}$-form. The limit between sinus and atrium is not very clear. This part is lying at the ventral side and is stretched in oblique-longitudinal direction. The dorsal ventriculus shows a clear nod and runs in transverse direction. It passes into the ventral aorta and into the vessels of the visceral arches. The two venae omphalomesentericae discharge into the sinus venosus and pass at the distal side into the bloodvessel complex of the yolk sac. The ductus Cuvieri and rudiments of the venae candinales are present (see fig. 9c).

The "Anlagen" of the neural tube shows three brain vesicles: prosencephalon, mesencephalon and rhombencephalon, and probably the rudiment of the optic vesicles. The rhombencephalon shows four rhombomeres. The neural tube is not yet closed at the caudal end of the rhombencephalon and at the beginning of the medullary tube. The foremost neuroporus is already closed. At the caudal end the medullary tube is still open and the neural plate is still visible. This hindmost part of the neural plate probably will not form a part of the nervous system but supplies the material for the canalis neurentericus, the tailgut and a part of the epidermis of the tail.

\section{IV-THREE-LAYERED BLASTOCYST}

with well developed embryonic region, much more developed as in stage of N. 6 . \pm 25 somites are present. Neural tube completely closed, for the rest the encephalon is not very strongly differentiated. Greater part of blastocyst formed by exocoel. Allantois well-developed, attached to the ectoplacenta. The mouth plate is lacerated, 3 visceral pouches, present in this stage, are closed (uterus 8 ).

Uterus 8 shows at one side a little swelling, at the other side a much larger one ( $7 \mathrm{~mm}$. in section). The largest dimension of the knob is perpendicular to the longitudinal direction of the uterine horn. The plane of section is perpendicular to this largest dimension and \pm parallel to the horizontal plane of the embryo. As the embryonal region is curved and shows a torsion in the horizontal plane, this statement must be taken cum grano salis.

The placenta is rather voluminous $\left(3 \frac{1}{2} \times 3 \times 2 \frac{1}{2} \mathrm{~mm}\right)$ i.e. much larger than the embryonic region.

The mouth is open, the pharynx shows three closed visceral pouches. The first pair of visceral pouches is very large and the ectodermal invaginations corresponding to it are very deep and grow together with the wall of the first 


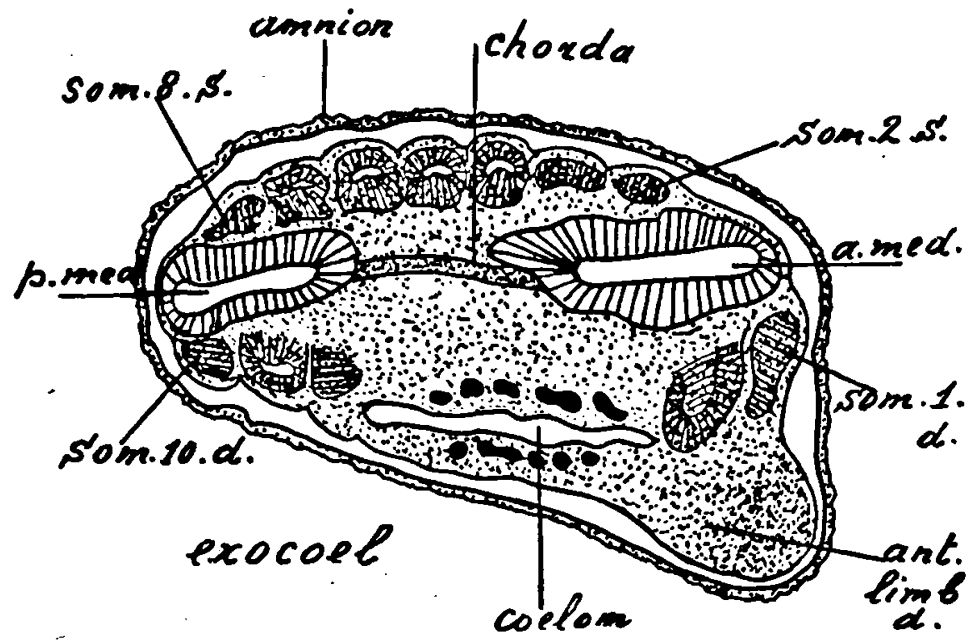

Fig. Ioa $\times 4$.

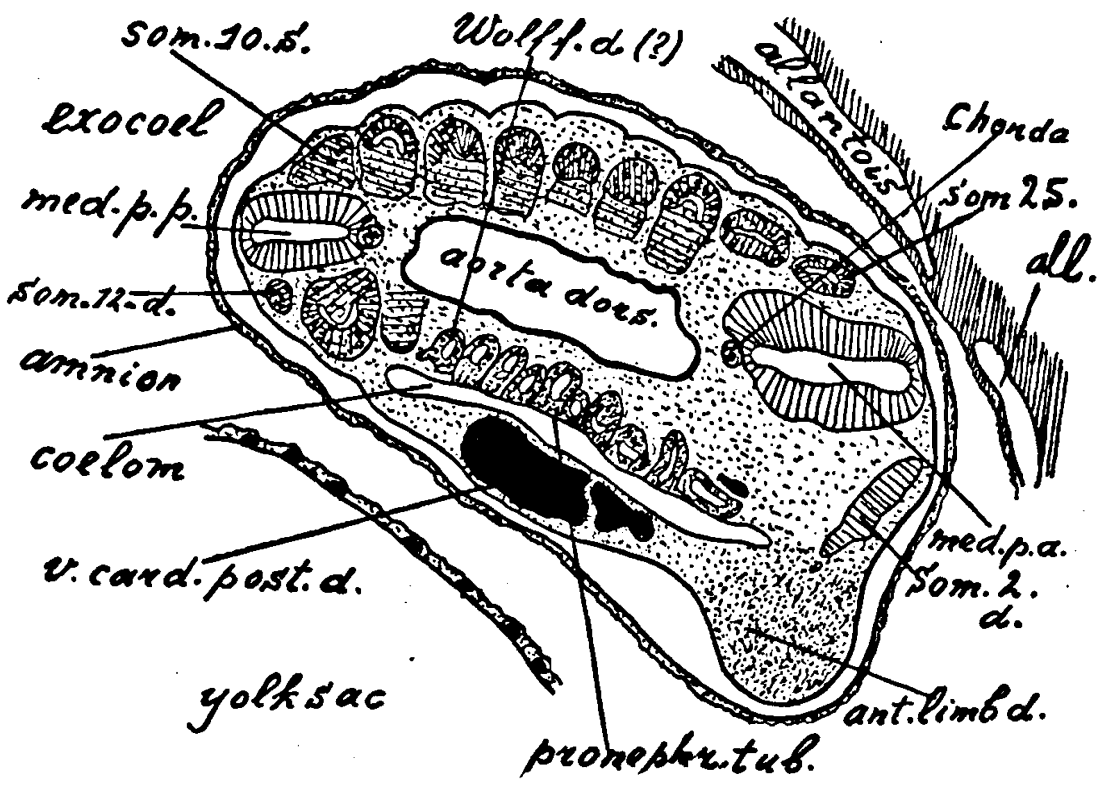

Fig. Iob $\times 40$. 
visceral pouch but the visceral plate remains intact. Probably in consequence of the plane of section the thyroid gland is not to be seen, as was the case in stage 6 (fig. $9 \mathrm{~b}$ ).

Three aortic arches are visible. The heart rudiment shows a clear S-form. The ventriculus is continued in the three above-mentioned aortic arches which unite on both sides into two radices aortae. An unpaired dorsal aorta is not yet present. The venous system shows not the common type but one gets the im-

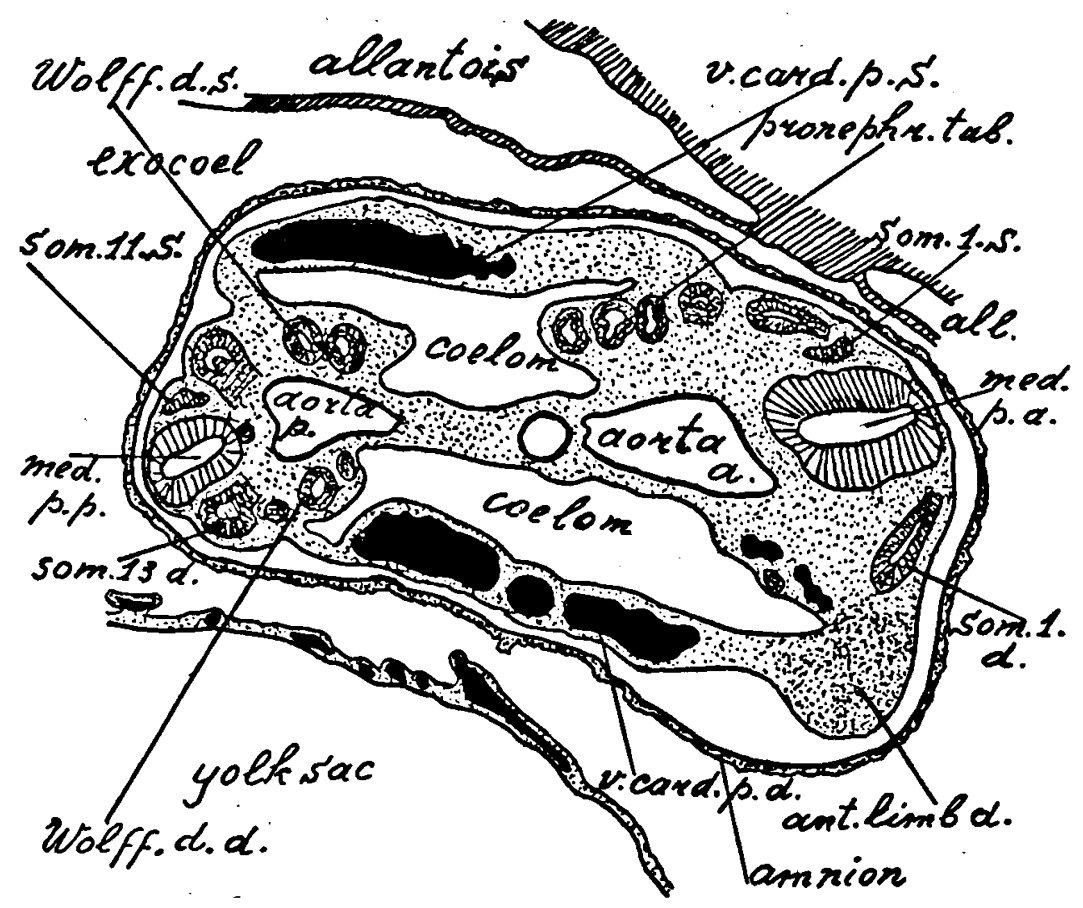

Fig. Ioc $\times 40$.

pression that a closed system of blood vessels including the circulation of the allantois is present. The venous system is not very distinct and is connected at some spots with the arterial system f.i. at the foreside of the pharynx and in the allantois venae and arteriae cannot be distinguished very clearly. The venae cardinales and the ductus Cuvieri are much less clearly visible than in stage 6. Probably this phenomenon is caused by the difference of direction in the plane of section. The two venae omphalomesentericae are rather wide at their mouth into the sinus venosus but the right one is much larger than the left one.

The S-shaped curvature of the heart is much more distinct than in the foregoing stage. The ventriculus is lying free in the pericardial cavity but at the oral side it joins the dorsal part of the pericard and passes into the truncus aortae. The pericard is well developed and rather large. The pericardial cavity 
is in direct connection with the peritoneal one and with the exocoel. One may distinguish nearly 25 somites. A pronephros or a Wolffian duct are not yet present. The pharynx is rather long. It is cut in longitudinal direction (more or less horizontal). So in some sections the visceral pouches on both sides are visible. Remains of the lacerated mouth plate are still present.

The yolk sac is rather narrow and is connected with the midgut by a likewise narrow yolk stalk. The lumen of the midgut is very narrow but at the caudal side it widens to the cloaca which passes into the cavity of the allantois. An intact anal plate is still present. The mesodermal allantois is grown together with the fetal side of the ectoplacenta. This structure shows not yet

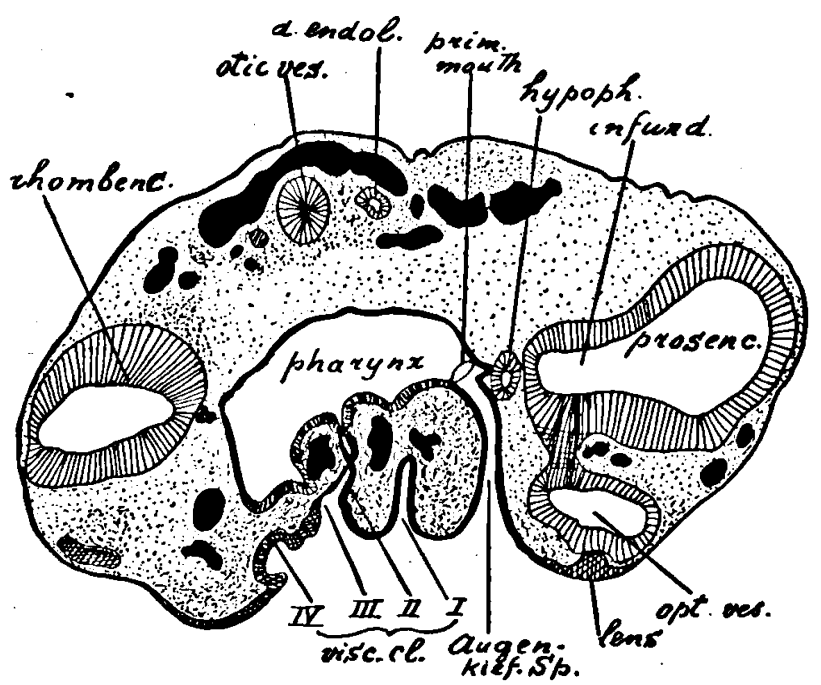

Fig. $\operatorname{lod} \times 35$.

mesodermal villi with real blood vessels but blood lacunes probably filled with maternal blood are present.

At the fetal side one may find large lacunes with a very thin wall, at the uterine side and in the centre the lacunes are much smaller and possess a multilayered wall (plasmodi- and cytotrophoblast?). A central maternal artery of a certain extent pours the maternal blood into the large lacunes and this blood is removed at the uterine periphery of the placenta into venous cavities which are connected with the maternal venous system by venae passing through the placentar hilus.

The neural tube is completely closed. A clear rudiment of the optic vesicle is present. It is still in connection with the exterior by a rather narrow stalk. 2 or 3 rhombomeres are indistinctly visible, probably a rudiment of the epiphysis is present. The limits of the 3 brain vesicles are not very clear. The infundibulum is present but the hypophysis is still wanting. 


\section{V-BLASTOCYSTS WITH RATHER WELL-DEVELOPED EMBRYO}

(Uterus N. I) This uterus shows 3 swellings. The volume of these swellings is rather equal. The swelling $\mathrm{ra}$ and $\mathrm{rb}$ are cut into serial sections, swelling $\mathrm{c}$ is still intact. Ia possesses a plane of section perpendicular to the longitudinal axis of the uterus, that of $\mathbf{I b}$ is cut more or less parallel to it. As the situation of both embryos in the blastocyst is not quite the same, the

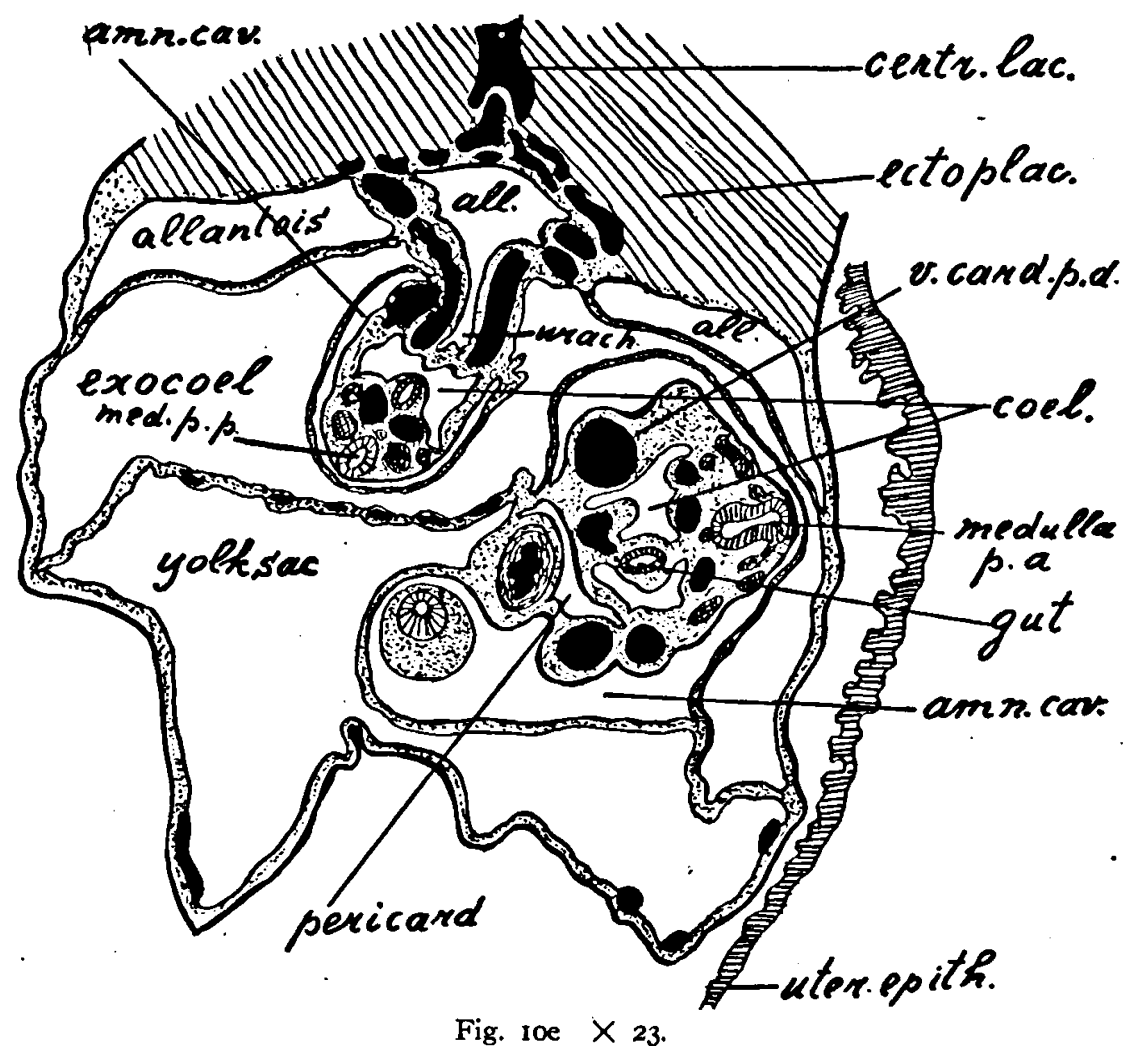

plane of section in both cases is not so very different. In Ia the plane of section is, however, horizontal in the midtrunk while in $\mathrm{rb}$ the hindmost part of the head region and the foremost part of the trunk are horizontally cut.

30-35 somites, 3-4 aortic arches, 12 nephric tubules and the rudiments of the foremost extremities are present.

Series Ia. On the inner surface of the placenta the allantois is lying, then follows the exocoel and the free half of the blastocyst is filled up with the yolk sac which is much larger than in N. 8. The embryonic region surrounded by the narrow amniotic cavity is lying between the exocoel and the yolk sac (see fig. IOa-c). The yolk stalk is very short and rather narrow so that 
the enteric tube and the cavity of the yolk sac are almost disconnected (see fig. rof). The gut is formed by a narrow mid-enteron which is not in open connection with the yolk stalk.

In further sections the midgut is dividing into the orally lying pharynx and the hindgut situated almost perpendicularly to the midgut. The anal plate is

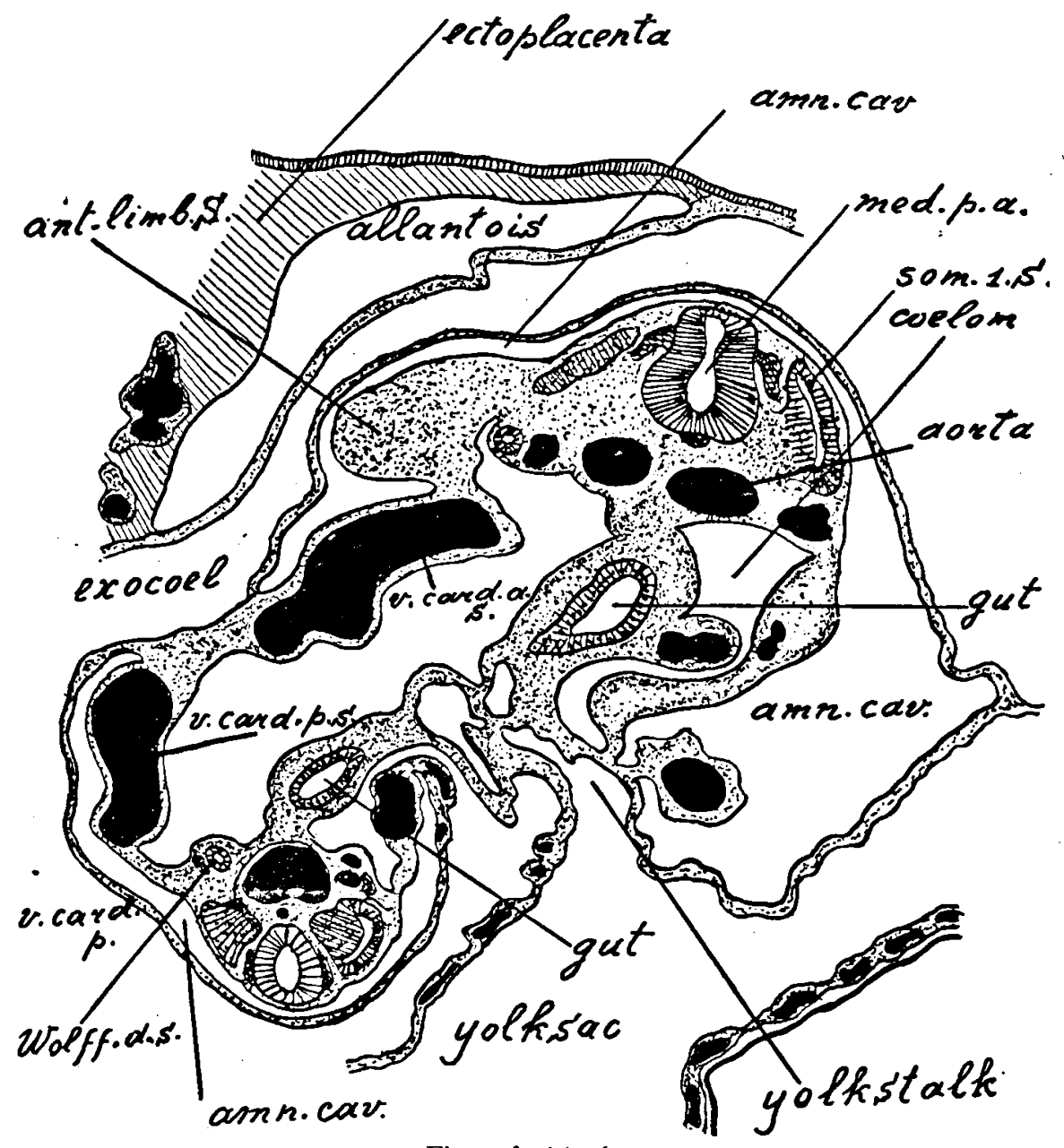

Fig. Iof $\times 46$.

lacerated (probably artificially). It is rather long but narrow. Behind the anal plate a short tailgut is present which passes into a teloblastema. Before the anal plate a narrow connection of the allanto:s with the hindgut, a short urachus is visible (see fig. Ioe).

The fore part of the midgut shows the solid outgrowth of the liver. The length of this rudiment amounts to $240 \mu$. Perhaps a slight swelling of the fore part of the midgut may be considered as the rudiment of the stomach. 
A slight rudiment of trachea and lung may be observed. The pharynx shows 3 visceral pouches, the last one being little developed. The pharynx is rather large.

The central nervous system is well-developed. The medulla shows a dorsal ganglionic outgrowth of continuous character which is ventrally divided into separate spinal ganglia. At the caudal side it passes into the neurenteric string which is connected with the teloblastema. At the hindpart the medulla shows a torsion and is curved in the same way as the embryonic region.

At the foreside the spinal tube passes into the encephalon. The latter shows

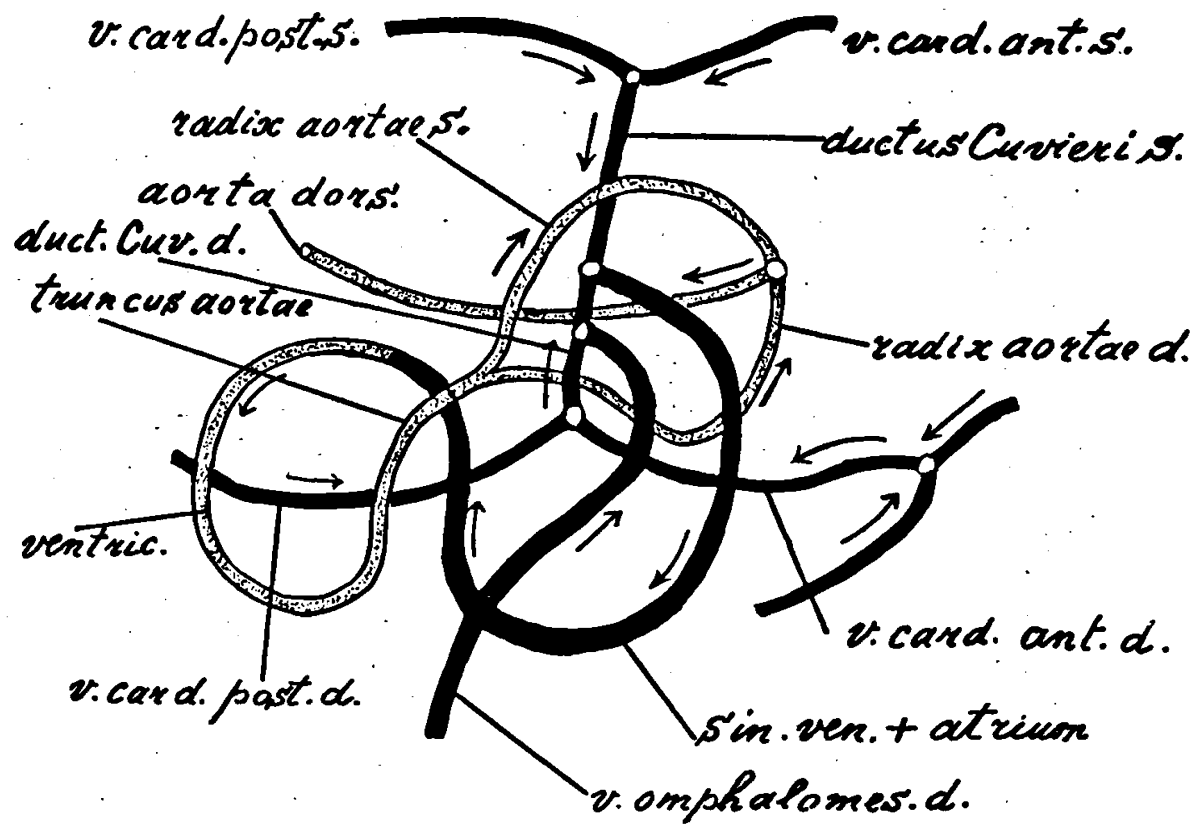

Fig. Iog

a semicircular arrangement and the prosencephalon is twisted so that the left part projects in dorsal direction above the right one. This part of the brain shows well-developed optical vesicles connected with the cavity of the forebrain by narrow optical stalks. Lens placodes are present.

A well-limited mesencephalon is not visible in this series. Perhaps this phenomenon is caused by the plane of section. The epiphysis is also wanting. The rhombencephalon is well-developed and shows about 6 rhombomeres.

In the "Augenkieferspalte" (the cleft between the brain base and the visceral region) a clear rudiment of the ectodermal hypophysis is visible in the form of a little sac opening into the amniotic cavity and lying against the infundibulum (see fig. Iod). 
The otic vesicle shows a rudiment of the ductus endolymphaticus but there is no connection of its lumen with the exterior.

The brain ganglia of V, VII, IX and $\mathrm{X}$ are present. The ganglion of the trigeminus is very large, that of the facialis is slightly smaller, that of the glossopharyngeus is very small and that of the vagus is moderate.

The ganglia of IX and $\mathrm{X}$ show a narrow connection. In the trunk several spinal ganglia are present, the number agreeing with that of the corresponding somites.

The vascular system is well-developed. A true aorta dorsalis lying ventrally to the very narrow chorda is present. At the fore side it divides into the two radices aortae, at the hind side into the two arteriae caudales.

The structure of the heart is very complicated (see the schematic reconstructure of fig. Iog). Two ducti Cuvieri are present, the left one is rather long, the right one is short. They separate the cardinal veins into an anterior and into a posterior portion. The right anterior cardinal vein divides once more into a posterior and an anterior. On the left side this is not the case. The right vena omphalomesenterica has developed into a large vessel and discharges into the ductus Cuvieri. Sinus venosus and atrium show no clear limit and pass continually in each other. Ventriculus and sinus venosus + atrium are twisted round another, the former propelling the blood forward towards the truncus and the radices aortae, the latter is directed caudally in an S-formed curvature. The wall of the ventriculus is formed by an inner spongious and an outer compact layer. The ventriculus passes into the truncus aortae. The first aortic arch may be considered as an anterior branch of the second one and these two vessels unite together with the truncus aortae. The first arch does not participate in the formation of the radix aortae but is forming the arterial system of the head region: the arteria carotis communis with its derivates (a. carotis externa and interna etc.). Of the remaining arches (2-4) it is not sure if they unite to form the radix aortae; one gets the impression that these arches are ending blindly and are not yet in communication with the radices aortae.

I will describe the vascular system of the allantois separately. As I mentioned above, the allantoic sac is lying between the placenta and the exocoel. The latter is nowhere in contact with the placenta as is the case in N. 8a. Consequently it is necessary for the connection of the embryonic region and the placenta (by foetal vessels) that the allantoic sac is pierced by four strings: two large central ones lying on both sides of the urachus and passing into the umbilical cord and two smaller ones at the anterior and posterior side of the allantois. The vessels of the central strings unite as they reach the embryonic region and the arteries run at the medial side of the coelom towards the arteriae caudales. The large allantoic vein unites with the vena cardinalis posterior sinistra which is very large. On the right side there is no connection between the umbilical system and the vena candinalis posterior dextra which is much smaller than the left one. The small vessels of the strings 3 and 4 show a 
connection with the umbilical system. The allantois therefore possesses 5 evaginations or in other words consists of 5 bladders. The venous system consists of a large trunk with two supplying smaller veins and plunges into the large v. card. post. sin. The arterial system consists of two large umbilical arteries which remain separated and unite with the arteriae caudales, one with the right and one with the left one.

\section{THE STRUCTURE OF THE PLACENTA}

The connection of the blastocyst with the uterine wall takes place by the ectoplacenta which contains a system of lacunes filled with maternal blood and with walls of trophoblastic origin (probably plasmoditrophoblast). The foetal side of the ectoplacenta shows a thin layer of foetal mesoderm containing foetal blood vessels, a kind of placental labyrinth. Placenta and blastocyst are suspended to the uterine wall by a complicated mesoplacentarium as in younger stages. By this configuration blastocyst, ectoplacenta and the roof of the placenta are rather movable.

The material decidua shows large blood sinus and large ferriferous cellmasses (glands?) which are coloured green by picro-indigo carmin. The degenerate uterine epithelium at the spot where the attachment of the trophoblast to the uterine wall takes place is also coloured green. These ferriferous cell-masses form an organ system situated on both sides of the mesometrium. The trophoblast has grown together with the uterine epithelium in a circular zone. Both tissues are changed into a foeto-maternal symplasma of ferriferous degenerated cells. In the centre of the attachment the symplasma is wanting and a direct attachment of trophoblast and placenta roof is present. Through the ectoplacenta penetrates a large central lacune towards the foetal side dividing into a system of much narrower lacunes.

Finally I shall mention here some facts about the somites and the tubuli of pro- and mesonephros (figs. Iob, c, and f). In the midtrunk the sections of N. Ia are cut in a horizontal plane. We may see on both sides a row of 8 à 9 somites. These are disappearing in the middle part. Some sections more ventral they are replaced by 6 or 7 nephric (probably pronephric) tubules. On the fore side we may distinguish one somite, on the hind side two or three ones. Thus one cephalic somite, two or three trunksomites (N. 8, 9 and 10) and six or seven intermediate pronephric tubules are visible, the latter showing a clear connection with short longitudinal veins disappearing after some sections. The pronephric tubules are showing then a clear lumen and connections with the wall of the coelom. The hindmost of these vesicles is probably the Wolffian duct. It penetrates in the urogenital fold and is visible on the fore side. How both parts of the Wolffian duct are connected is not very clear but it may take place through the tubules of the pronephros. The Wolffian duct may be continued till the region of the hindgut but it shows not yet a connection with hindgut or cloaca. It possesses a blind posterior ending in the region where the 
urachus is connected with the hindgut. The nephric rudiment backwards to the formation of the Wolffian duct shows the typical structure of the mesonephros with coiled tubules and is lying in a rather large urogenital fold. Of course the mesonephric tubules are wanting in the tailregion. As was already mentioned more than 30 somites are present.

Series $\mathrm{I} b$ possesses a plane of section parallel to the longitudinal axis of the uterus. This plane thus is perpendicular to that of the series ra. As the situation of both embryos in the uterus is not quite the same the relations of these planes of section concerning the embryonic region does not agree with our expectation. The sections are more or less symmetrical. The embryo shows three bendings, one in the region of the mesencephalon, one in the foremost part of the trunk (in the neck region) and one on the limit of trunk and tail. The sections are more or less horizontal in the region of the bendings and transverse in the other parts.

As a rather large number of sections is lacerated the number of somites cannot be estimated exactly but probably it will be of the same order as in Series Ia (30-35 somites). Generally spoken the state of development in both series is quite the same f.i. heart and pericard, nephric rudiment, brain with optic vesicles, lens, hypophysis, otic vesicles. The olfactive placode c.q. invagination is not yet present. The placenta in both series makes a similar impression. The greater part consists of ectoplacenta covered on the embryonic side by a thin labyrinth. A large central lacune is present which communicates with the maternal arterial system. The blood passes through the labyrinth, exchanges material with the foetal capillaries and obtains connection with the maternal venous system at the lateral side of the placenta.

\section{VI-BLASTOCYSTS WITH WELL-DEVELOPED EMBRYO}

Finally I will give a short description of uterus 3 which shows 3 swellings rather the same dimensions. The swelling $3^{a}$ is cut into sections, the plane of section being transverse to the longitudinal axis of the uterus. The other two swellings are still intact. The surface of the attachment of the foetal placenta to the uterine wall is rather small and the development of the vascular lamina of the mesoplacentarium is much smaller than in the object N. I. The vascular lamina and the enlarged uterine glands are lying at the embryonic side of the blastocyst.

The greater part of the uterine wall and of the blastocyst show a free surface. The embryo fills up the main part of the blastocyst and its volume is much larger than that of object N. I. (See the reconstruction of N. 3, fig. Ira).

The yolk sac is more or less shriveled and shows the form of a toad-stool. It possesses a yolk stalk with rudimental lumen. There is, however, no direct 


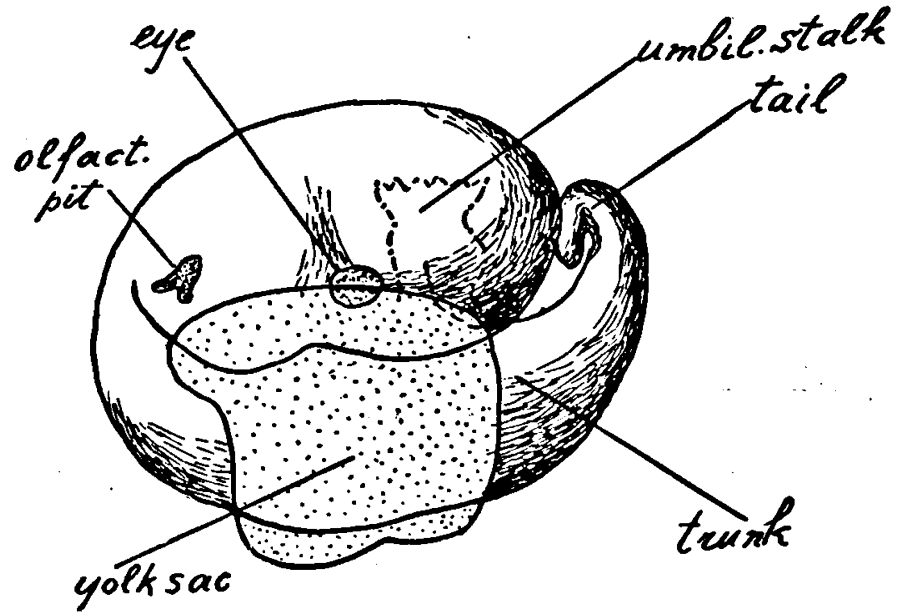

Fig. 11a $\times$ io.

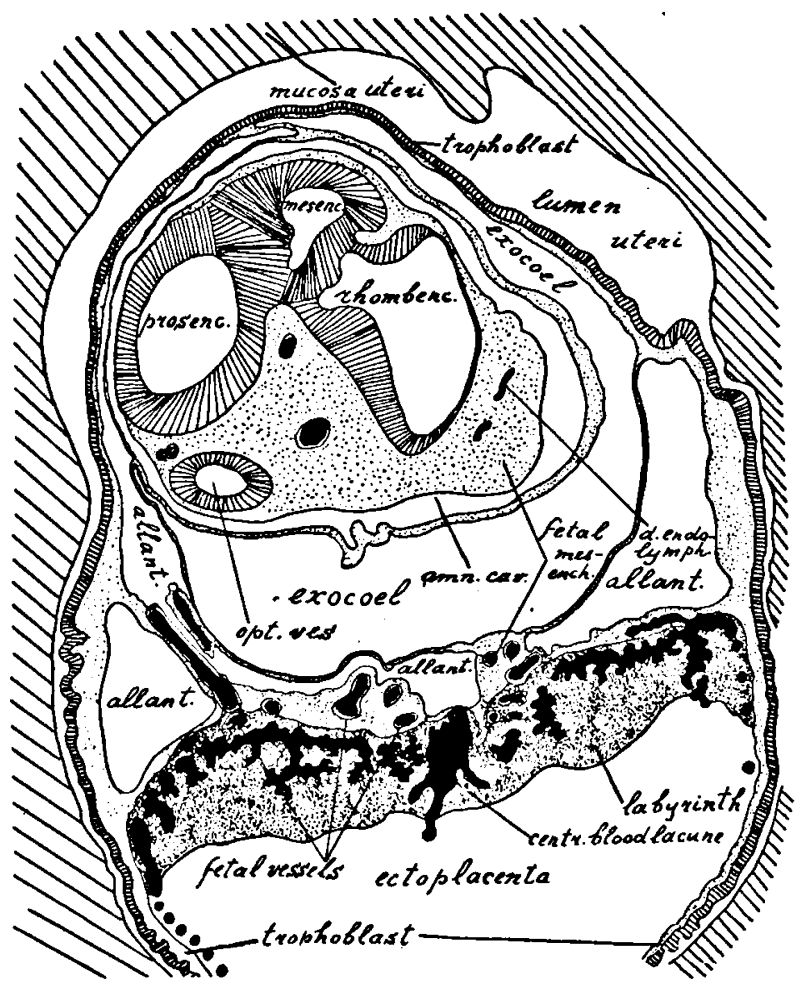

Fig: IIb $\times 12$. 
connection between the enteric lumen and that of the yolk sac (see fig. IIa).

The exocoel is for the greater part pushed aside by the allantois, which has grown around the amniotic cavity. The allantois shows four lobes separated by the 5 lamellae containing allantoic vessels. The large middle lamella forms the real allantoic stalk (umbilical cord) which contains the urachus and the large allantoic vessels (fig. IIb \& c). In the reconstruction only the umbilical cord is represented but the allantoic lobes are wanting.

The placenta is very extensive. Length and breadth agree with the same dimensions of the blastocyst. It principally contains ectoplacentar tissue but at

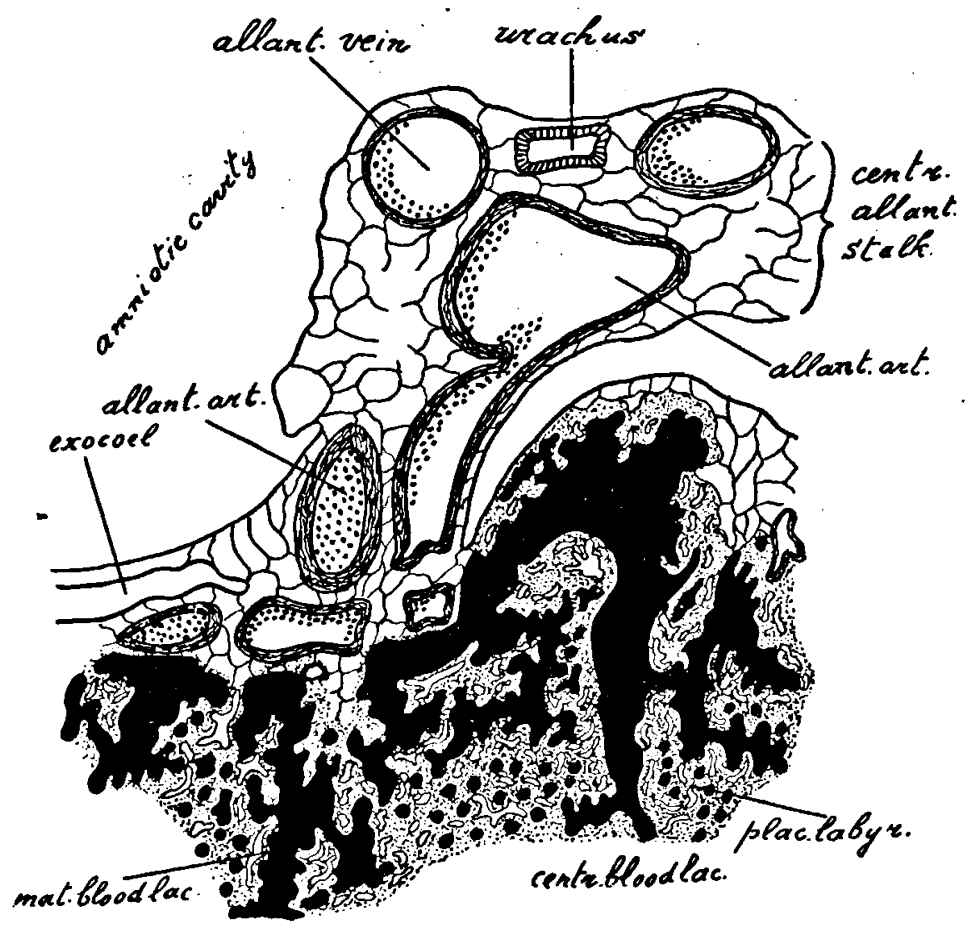

Fig. IIC $\times 30$.

the fetal side a rather thick layer of placentar labyrinth is present (see fig. IIb). At the inner side of the labyrinthic conus large ectoplacentar lacunae and fetal capillaries form a meshwork. These central lacunae are filled with maternal blood derived from the large central maternal artery. The blood of these central lacunae flows off to the large lateral lacunae of the ectoplacenta which are connected with the maternal uterine veins.

The ring of synplasmatic tissue is more or less wanting but here and there islands of symplasma are present. Connections between the uterine wall and the fetal placenta are seen at the spots where the central maternal artery penetrates into the ectoplacenta and where the maternal veins are leaving it. The embryo is strongly coiled especially in the head region which is folded in a 
way that the basis of the prosencephalon is lying against the basis of the rhombencephalon. The nod in the neck region, however, is not very conspicuous. The short tail region is separated from the trunk by a small nod. A distinct torsion of the embryonic region has taken place but it was not possible to

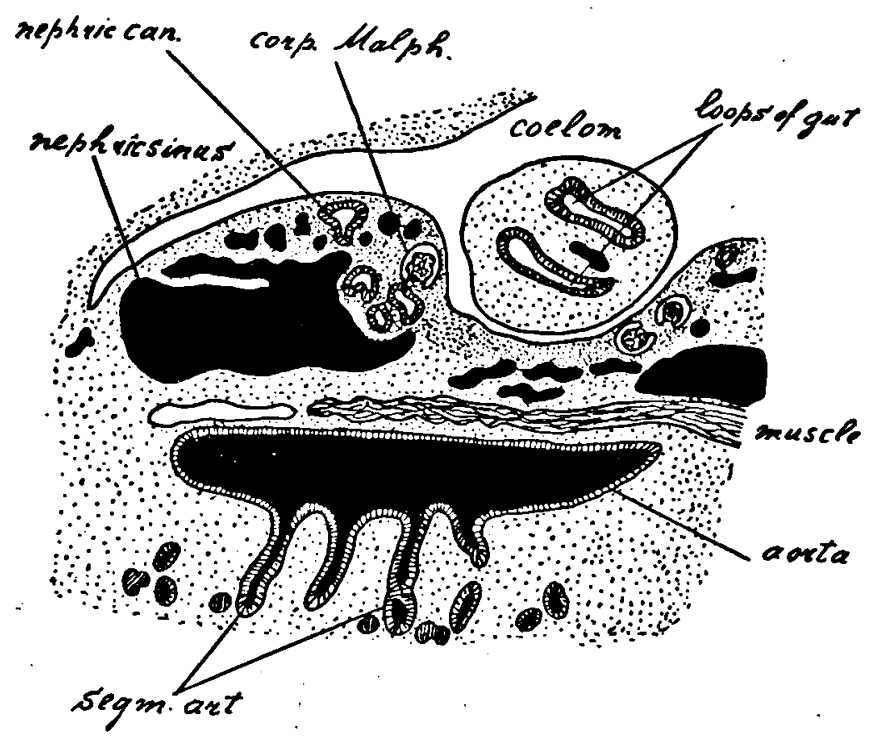

Fig IId $\times 30$.

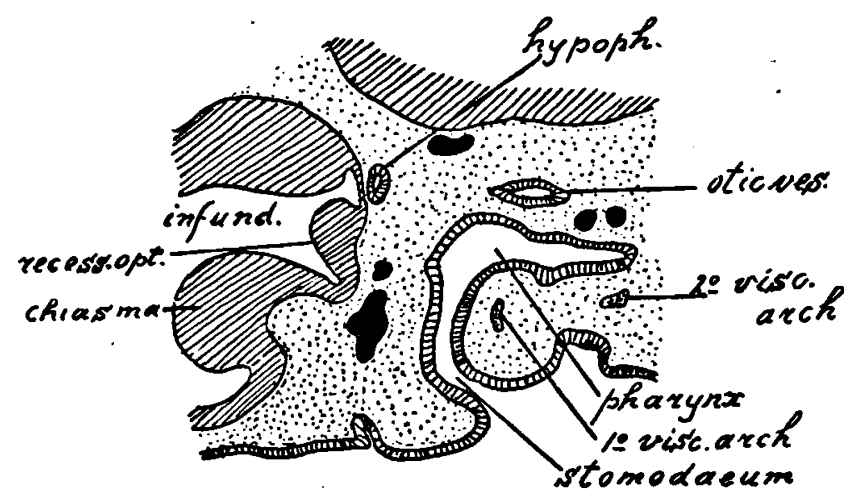

Fig. Ire $\times 8$.

indicate this phenomenon in the reconstruction. The development of the embryo resembles that of the object $\mathrm{N}$. I.

The number of spinal ganglia (these are more distinct than the somites) amounts to 30-35 and 8 à 9 nephridial segments are present but these are more differentiated than in the object N. I. Large blood sinus which are in con- 
nection with the aorta are present at the base of every segment and Malpighian corpuscula are to be seen (fig. I Id).

Anterior and posterior limb rudiments are present. In the anterior ones some parts of the skeleton (upper arms, under arms and hands) are already to be seen. The posterior ones are rather tall but the differentiation of the skeleton has not yet begun.

The encephalon shows a distinct coiling up and a torsion. By these phenom.

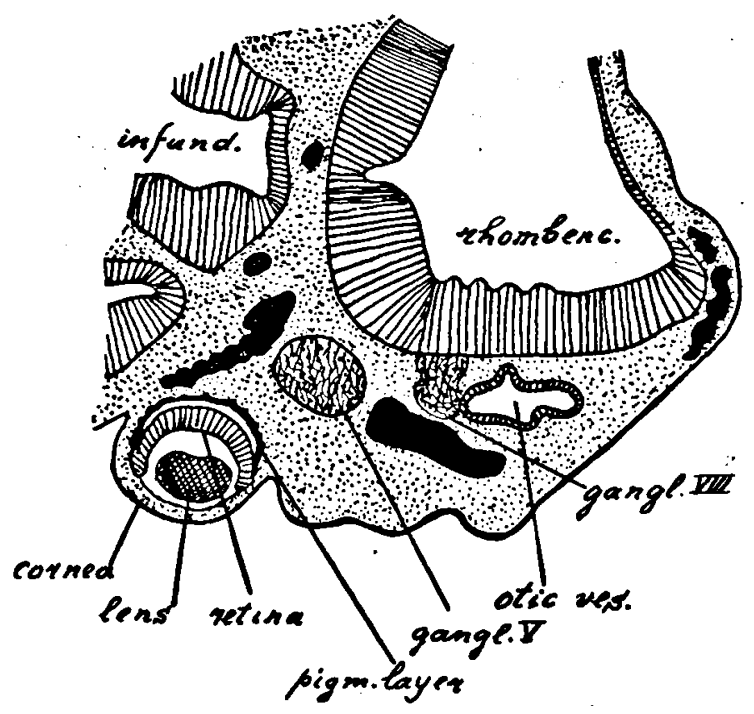

Fig. IIf $\times 8$.

ena the sections show a confuse image. I have not been able to discover the rudiment of the epiphysis but a distinct hypophysis is present. It is formed by a close vesicle connected with the epithelium of the mouth by a solid stalk (see fig. IIe). The rudiment of the eye is very small. An optic stalk with a narrow lumen is in connection at one side with the lumen of the encephalon (in the recessus opticus) at the other side with lumen of the optic vesicle. The thick retina at the interior side and the thin pigmented layer at the exterior side of the optic cup may be distinguished. The lens has separated from the epiblast. Between lens and retina the rudiment of the corpus vitreum is present (fig. IIf).

The otic vesicle has disconnected from the epiblast but a blind ductus endolymphaticus and three bulges, the rudiments of the canales semicirculares, are present (fig. IIf). Probably the oblique plane of section and the torsion of the embryo are cause that the fixation of the number and the configuration of the visceral pouches is very difficult. Probably three visceral pouches and visceral arches are present. None of the pouches open to the exterior. 


\section{SUMMARY}

I. In Macroscelides (Elephantulus?) rozeti Duv., a North-African form, the pregnant uterus shows 3 swellings (sometimes this number is reduced to $I$ or 2). The South-African form Elephantulus myurus Jamesoni, examined by prof. VAN DER HORST (Johannesburg) always shows two swellings, one in each half of the uterus horns.

2. The tuba is connected with a periovarial sac.

3. The eggs in the ampulla are naked and not surrounded by the zona pellucida. This causes sometimes the segmented cells to be set free.

4. The four-celled stage shows a tetrahedral arrangement.

5. In the uterus horn the unilaminar blastula is formed by the absorption of water.

6. In a stage of 120 cells the blastula-wall separates amoeboid cells into the interior forming a loose reticulum. Afterwands these cells concentrate at one side of the germinal vesicle and form the embryonic knot.

7. This organ separates an entodermal cell-layer at its base.

8. At the mesometrical side the germinal vesicle adheres to the uterine wall which is syncytial at this spot.

9. After the adhering of the germinal vesicle the mucosa uteri becomes very thick and the muscularis very thin. The small number of blood vessels in the mucosa is very remarkable.

ro. There is a marked increase of the number and extent of the uterine glands. The image resembles that of the secretory phase in man.

II. In the following stage (N. 45) the trophoblast has become very thick and has penetrated into the mucosa uteri. The embryonic knot shows a large archamniotic cavity.

I2. In $\mathrm{N}$. 6 the embryonic region shows 7 à 8 somites. A distinct pharynx is present. In the mid- and hindgut a large connection of enteron and yolk sac is present. Cloaca with allantoic evagination, a large, mesodermal, allantoic rudiment is present. The yolk sac forms about two thirds of the blastocyst, the remaining third part is formed by the exocoel and the amniotic cavity. A proamnion is present. Enlarged uterine glands surround the whole uterine cavity. A large ectoplacenta shows a toadstool-form and penetrates into the uterine wall forming a disc of foeto-maternal symplasma. Heart rudiment rather well developed.

13. N. 8. The embryo shows \pm 25 somites. Allantois well developed, adhering to the ectoplacenta. The greater part of the blastocyst is formed by the exocoel. Three visceral pouches are present, the mouth plate is lacerated. The neural tube is completely closed.

14. In N. I 30-35 somites and 12 nephric tubules are present. Rudiment of anterior extremity, 3-4 aortic arches.

I5. In N. 3 the yolk sac is much smaller and its walls are shriveled. A yolk 
stalk may be seen but the connection between the lumina of gut and yolk sac has disappeared. The allantois surrounds the amniotic cavity and fills up the main part of the blastocyst. It shows four lobes. The ectoplacenta shows a thick layer of labyrinthic tissue at the, embryonic side. The embryo is strongly coiled and possesses a distinct torsion. The kidney is well developed (with Malpighian conpuscula). Posterior extremities are present. In the anterior ones the rudiment of the skeleton may be noticed.

16. In the stages N. 45 and N. I a distinct mesoplacentarium consisting of numerous lamellae with bloodvessels is present at the mesometrical side of the uterine wall. As in the aguti (BECHER) this phenomenon may be in relation with the jumping propulsion.

\section{LITERATURE}

Becher, H., 192I. Der feinere Bau der reifen Placenta von Aguti (Dasyprocta azarae Schl.). Zeitschr. f. Anat. u. Entw.-Gesch., Bd. 6r, Heft r/2.

Gerard, P., I923. Etude sur les modifications de l'uterus pendant la gestation chez Nasilio branchyrhynchus. Arch. de Biologie, Tome 33.

- 1927. Contribution à l'étude du placenta maternel des Rongeurs. Arch. de Biologie, Tome 37.

HORST, C. J. VAN DER, 1942. Some observations on the structure of the genital tract of Elephantulus. Journ. Morph., Vol. 70.

—- 1943a. Early stages in the embryonic development of Elephantulus. South Afr. J. Med. Sci., Vol. 8.

- 1943b. The mechanism of eggtransport from the ovary to the uterus in Elephantulus. South Afr. J. Med. Sci., Vol. 8.

-1944. Further stages in the embryonic development of Elephantulus. South Afr. J. Med. Sci., Vol. 9.

- and J. Gillman, 1925. The number of eggs and surviving embryo's in Elephantulus. Anat. Rec., Vol. 80.

and - I 1944 . On abnormal blastulae in Elephantulus. Anat. Rec. Vol. 90.

LANGE, D. DE, 1921. Contribution to the knowledge of the placentation of the Cape Goldmole (Chrysochloris). Bijdr. tot de Dierkunde, D. XXI.

- 1922. Vorläufige Mitteilung über die Beschaffenheit der Ovarialtasche von Chrysochloris, Galeopithecus und Tupaia. Bijdr. tot de Dierkunde, D. XXII (Feestnummer Max Weber).

- 1938. Some remarks on the early development of Ctenodactylus Gundi. Arch. néerl. Zool. 3 (suppl.).

- 1939. Voorloopige mededeeling over de eerste ontwikkeling van de Noord Afrikaansche Springmuis (Jaculus). Natuurwetensch. Tijdschr., D. 21. 


\section{EXPLANATION OF FIGURES}

Fig. I. Schematic representation of ovarium, ovarial sac and Fallopian tube of Elephantulus myurus Jamesoni; after VAN DER HORST (1942).

Fig. 2. The genital tract of Elephantulus myurus Jamesoni; after vAN DER HORST and Gillman (194I).

Fig. 3. Young cleavage-stages of Elephantulus myurus Jamesoni; after vAN DER HoRST (I942).

a: one-celled stage with two pronuclei and two polar bodies; b: egg with first cleavage spindle; $c$. two-celled stage.

Fig. 4. Four-celled stage of Elephantulus myurus Jamesoni.

$a$ and $b$ : two sections; $c$ : reconstruction of a four-celled stage. The cells are arranged in a circle; $d$ : reconstruction of a four-celled stage with one polar body and tetrahedral arrangement of the cells.

Fig. 5. Formation of blastula and embryonic knot in Elephantulus myurus Jamesoni; after VAN DER HoRsT (1943).

a: four-celled stage with rudiment of blastocoel; b: blastula with 32 cells; c: stage of 120 cells, amoeboid central cells detaching from wall of blastula; d: central cells forming a loose reticulum.

Fig. 6. a : concentration of central cells forming the embryonic knot, some dark-coloured entoderm cells; $b$ : the same stage as a, somewhat more developed; $c$. blastocyst with spherical well-circumscribed embryonic knot; d: embryonic knot with archamniotic cavity.

Fig. 7. Sections through N. 2. d.

a: central section of swelling $2 \mathrm{~d}$. with large mesometrical uterine glands and germinal vesicle attached to uterine syncytium (row 2, N. 15, $\times 30$ ); b: attachment of trophoblast to uterine syncytium (row 2, 10, $\times 100$ ).

Fig. 8. Two sections through 45 a with mesoplacentarium, trophospongia and archamniotic cavity.

a: section through uterine swelling with mesometrium, mesoplacentarium, small antimesometral uterine glands and trophospongia. (gl. 14, row 3, N. 6, X 40); $\mathrm{b}$ : blastocyst with thickening of trophoblast, archamniotic cavity and yolk sac. Uterus wall, partly epithelial, partly syncytial with trophospongia (gl. 14, row 3, N. $8, \times 100)$.

Fig. 9. Sections through uterine swelling $6 a$ with ectoplacenta, mesometrium, mesoplacentarium and distal part of uterus. Large connection between gut and yolk sac. a : myometrical glands, mesoplacentarium spreading round the whole fruit chamber, blastocyst consisting of ectoplacenta and exocoel only (gl. I, row 2, N. 7, $\times 17) ; b$ : oblique sagittal section through head and neckregion with \pm 8 somites, pharynx with rudiment of thyrroid, ventricle and sinus venosus (gl. I7, row $I$, N. $4, \times 30)$; c: sagittal section through wide open gut with free allantois in exocoel, mesodermal allantois larger than entodermal one, \pm 4 somites and v. cardinalis posterior are visible (gl. 17, row I, N. 4, $\times 40$ ).

Fig. 10. Horizontal sections through an embryo with \pm 30 somites and \pm 12 nephric tubules and rudiment of forelimb. The five-lobed allantois is well-developed and has disloged the exocoel from the surface of the placenta. There are 4 attachments of the allantois to the placenta, the central one containing the urachus is the real umbilical stalk (Macroscelides $\mathrm{Nr}$. I).

a : section with undivided chorda and 7 somites at the left side (gl. 10, row 2, Nr. 8, $\times 40$ ) ; b : large aorta dorsalis, to the left side \pm 9 somites, to the right side \pm 12 nephric tubules and coelom (gl. Io, row 2, N. 16, $\times$ 40); c: aorta dorsalis divided, coelom also to the left side, venae cardinales posteriores visible at both sides (gl. 10, row $3, \mathrm{~N} .13, \times 40$ ) ; : horizontal section through pharynx (somewhat obliquely) at the left side otic vesicle, at the right side optical vesicle with lens, hypophysis. Pharynx with open mouth and 3 à 4 visceral pouches still closed (gl. 12, row 3, N. II, $\times 35$ ); e: central allantois with urachus, two lateral allantoic lobes (gl. I I, row 3, N. $7, \times 23$ ); $f$ : gut divided in fore- and hindpart. 
Large, central exocoel, yolk stalk not opening in gut, lateral allantoic lobe. (gl. II, row $2, N$. $4, \times 46)$. $g$ : schematic representation of the heart and its vessels. Fig. II. Reconstruction and sagittal sections through a well-developed embryo $(5 \times 5 \times$ $4 \mathrm{~cm}$ ) with \pm 35 spinal ganglia and 8 à 9 nephridial segments. The embryo fills the greater part of the blastocyst. Large placenta with well-developed labyrinth. Four allantoic lobes having pushed aside the exocoel.

a : reconstruction of the embryo and yolk sac. The allantois has not been represented, only the umbilical stalk, $X$ I0; $b$ : sagittal section through head region and part of the placenta with thick labyrinthic layer. 3 allantoic lobes and a lateral connection of allantoic vessels with the placenta are visible (gl. 20, row I, N. 6-7, $X$ I2); c: central allantoic stalk and urachus are visible (gl. 19, row I, N. I-2, $X 30)$; $d$ : section through aorta with segmental arteries and nephridial rudiments with corpora Malpighii (gl. II, row 3, N. 7, $\times 30$ ) ; e: pharynx, mouth, hypophysis and otic vesicle. First and second visceral arches are visible (gl. 17, row 2, N. 3-4, $\times$ 8); f : optical vesicle with lens, retina, pigmented layer and cornea are visible. Rhombencephalon with gangl. V and VIII and otic vesicle are visible (gl. 18 , row 4 , N. $5, \times 8$ ).

\section{ABBREVIATIONS}

all. (s. allant) : allantois

all. a. : allantoic arteries

allant. art. : allantoic artery

a. med. : anterior medulla

amn. cav.: amniotic cavity

amp. p. : ampullar part of tuba

a. p. med. : anterior part of medulla

ant. limb. : anterior limb rudiment

aorta dors.: aorta dorsalis

archamn. cavity: archamniotic cavity

attachm. : attachment

Augenkiefer Sp.: Augenkieferspalte

bloodv. : bloodvessels

centr. allant. stalk : central allantoic stalk.

$\mathrm{I}^{\circ} \mathrm{cl}$. sp. : first cleavage spindle

coel. + peric.: transition of coelom in pericard.

coagul. : coagulum

corp. Malp. : corpus Malpighii

d. : dexter or ductus

d. endolymph. : ductus endolymphaticus

dienc. : diencephalon

d. Cuv. : ductus Cuvieri

ectoplac. : ectoplacenta

embr. knot.: embryonic knot

entod. cells : entoderm cells

fert. eggs: fertilized eggs

fimbr. ovar. : fimbria ovarica

foet. bloodv. : foetal bloodvessels

fruitch.: fruit chamber

gangl.: ganglion

germ. ves.: germinal vesicle

gl. thyr.: glandula thyreoidea hypobl. : hypoblast

hypoph.: hypophysis

infund. : infundibulum

isthm. p. tubae: isthmial part of tube

lat. allant. stalk : lateral allantoic stalk

lat. bloodlac. : lateral bloodlacunes

m. circ. : musculi circulares

mesenc.: mesencephalon

mesench. : mesenchym

mesom. : mesometrium

mesonephr. tub. : mesonephric tubules

mesov.: mesovary

m. long. : musculi longitudinales

most lat. all. stalk. : most lateral allantoic stalk

musc. cov. of tube.: muscular covering

of tube

narrow ut. gl. : narrow uterine glands

nephr. tissue: nephridial tissue

neurent. string: neurenteric string

olf. inv. : olfactory invagination

olf. pit: olfactory pit

opt. ves.: optical vesicle

otic. : otical vesicle

outgr.: outgrowth

ovar. 1. : ovarial lip

peric. cav. : pericardial cavity

periov. s.: periovarial sac

perit. cav. : peritoneal cavity

pigm. layer: pigmented layer of optical vesicle

plac. labyr.: placental labyrinth

p. med. : posterior medulla 
pol. b. : polar body

p. p. med. : posterior part of medulla prim. coel. : primary coelom prim. mouth : primary mouth pron. $(\imath, \hat{\delta})$ : pronuclei $(Q, \hat{\delta})$ pronephr. tub.: pronephric tubules prosenc. : prosencephalon rud. embr. knot.: rudiment of embryonic knot

rhombenc. : rhombencephalon

s. : sinister

segm. art. : segmental artery

sin. ven. : sinus venosus

som.: somite

troph.: trophoblast

troph. lac. w. mat. blood: trophoblastlacunes with maternal blood

trophobl. thickn.: trophoblastthickening

tr.sp. : trophospongia

tub. eggch.: tubal egg chamoar tub. uter. j.: tubal-uterine junction

umbil. stalk: umbilical stalk

unp. ut. : unpaired uterus

urach. : urachus

ut. eggch.: uterine egg chamber

ut. epith. : uterine epithelium

ut. gl. : uterine glands

uter. 1.: uterine lip

ut. lum.: uterine lumen

ut. muc.: uterine mucosa

vasc. lam. : vascular lamellae

v. all. : venae allantoideae

v. card. post. : vena cardinalis posterior

v. omphalomes. : vena omphalomesenterica

ventr.: ventriculus

visc. arch. : visceral arch.

visc. cl. : visceral cleft

wide ut. gl.: wide uterine glands

Wolff d.: Wolffian duct

yolks. : yolk sac. 